Document downloaded from:

http://hdl.handle.net/10251/97795

This paper must be cited as:

Delgado-Villanueva, KA.; Romero Gil, I. (2016). Environmental conflict analysis using an integrated grey clustering and entropy-weight method: A case study of a mining project in Peru. Environmental Modelling \& Software. 77:108-121. doi:10.1016/j.envsoft.2015.12.011

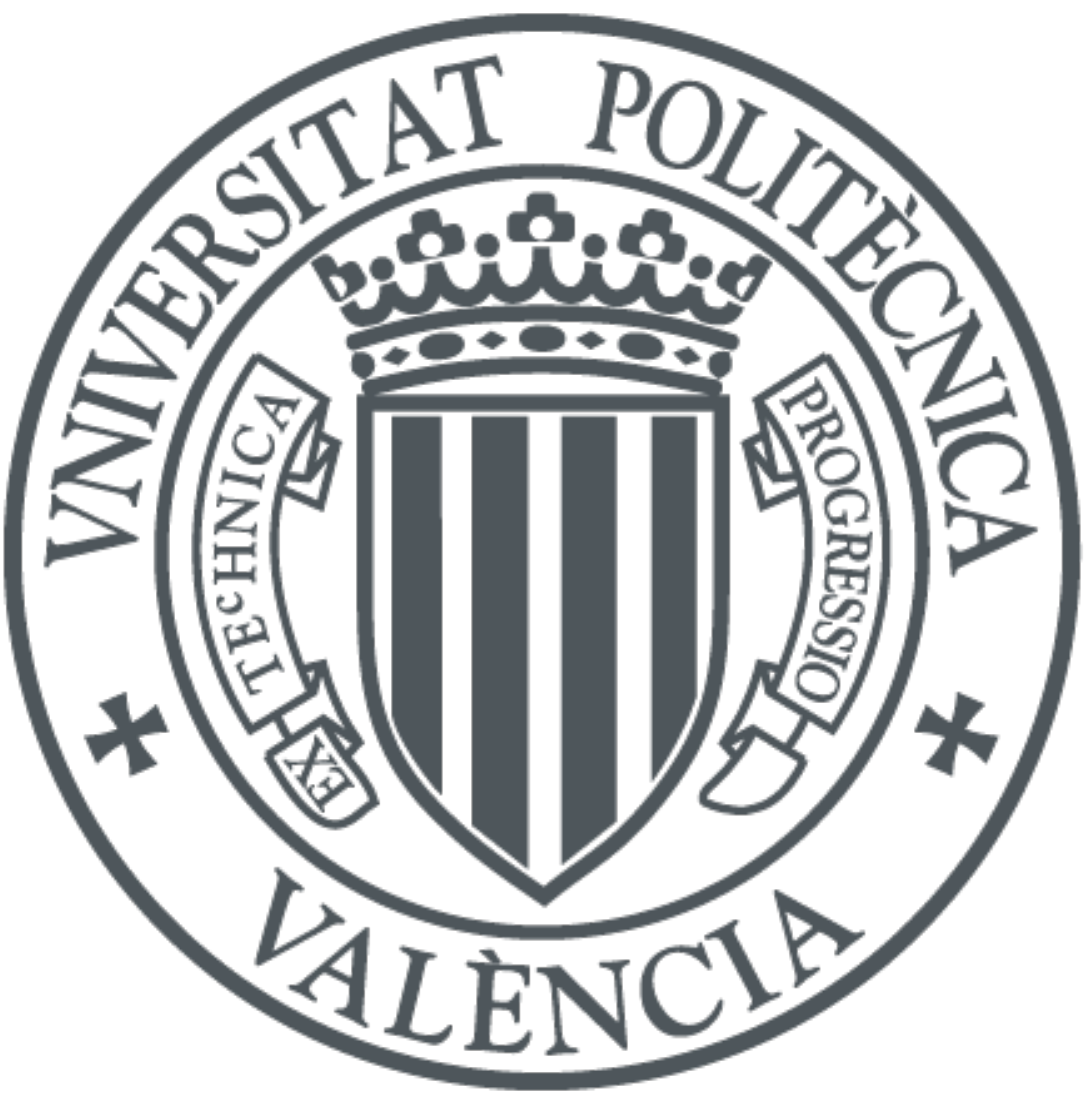

The final publication is available at

http://doi.org710.1016/j.envsoft.2015.12.011

Copyright Elsevier

Additional Information 


\title{
Environmental conflict analysis using an integrated grey clustering and entropy-weight method: A case study of a mining project in Peru
}

\author{
Alexi Delgado \\ 1.- Research Institute of Water and Environmental Engineering (IIAMA), Universitat \\ Politècnica de València, Valencia, Spain. \\ 2.- Faculty of Science and Engineering, Universidad de Ciencias y Humanidades, Lima, \\ Peru. \\ Address: Camino de Vera s/n, 46022 Valencia, Spain. Tel. +34963877616, Ext 76163. \\ e-mail: kidelvil@doctor.upv.es / alexidelgado@yahoo.es \\ Mobile: +34666979584

\section{Romero} \\ 1.- Research Institute of Water and Environmental Engineering (IIAMA), Universitat \\ Politècnica de València, Valencia, Spain. \\ Address: Camino de Vera s/n, 46022 Valencia, Spain. Tel. +34963877616, Ext 76163. \\ e-mail: inrogi@dihma.upv.es \\ Mobile: +34629861244
}

\section{ABSTRACT}

Environmental conflict analysis (henceforth ECA) has become a key factor for the viability of projects and welfare of affected populations. In this study, we propose an approach for ECA using an integrated grey clustering and entropy-weight method (The IGCEW method). The case study considered a mining project in northern Peru. Three stakeholder groups and seven criteria were identified. The data were gathered by conducting field interviews. The results revealed that for the groups urban population, rural population and specialists, the project would have a positive, negative and normal social impact, respectively. We also noted that the criteria most likely to generate environmental conflicts in order of importance were: access to drinking water, poverty, GDP per capita and employment. These results could help regional and central governments to seek appropriate measures to prevent environmental conflicts. The proposed method showed practical results and a potential for application to other types of projects.

\section{Keywords:}

Grey clustering method

Entropy-weight method

Environmental conflict

Social impact

Mining project 


\section{Introduction}

Environmental conflicts often accompany the planning and implementation of projects and programs, as evidenced by studies of conflicts related to water management (Bolin et al., 2008, Saqalli et al., 2010), energy (Fontaine, 2010, Karjalainen and Järvikoski, 2010), exploitation of natural resources (Correia, 2007, Warnaars, 2012, Madani et al., 2014) or ecological tourism (Yang et al., 2013). Therefore, organizations and governments require techniques enabling them to assess social impact and then, given this information, to propose measures for preventing environmental conflicts (Barrow, 2010, Prenzel and Vanclay, 2014). Organizations have obligation as part of their corporate social responsibility to evaluate their social impact to prevent possible conflicts within the affected communities (Kemper et al., 2013). Furthermore, governments are obligated to improve population welfare to achieve sustainable development of countries; therefore, they must measure social impact of their programs and state policies to prevent possible conflicts (Franks and Vanclay, 2013). In addition, stakeholders are a dimension of integrated assessment (Hamilton et al., 2015), and environmental conflicts are generated between stakeholder groups within communities, due to the differences in the assessment of industrial projects (Arun, 2008, Luyet et al., 2012). For this reason, social impact assessment must first be performed for each stakeholder group and then the gap between the groups must be determined in order to predict and prevent possible environmental conflicts.

Thus far, ECA has been mostly carried out using qualitative methods such as those described by Prenzel and Vanclay (2014, based on game theory), who address environmental conflict from an infrastructure development project, or by Griewald and Rauschmayer (2014, based on a capability perspective), who consider environmental conflict in a protected nature area. In addition, there are also quantitative methods for ECA, found, for example, in the study by Al-Mutairi et al. (2008, based on fuzzy logic) of environmental conflict over aquifer contamination caused by a chemical company. In this article, we apply a method for ECA combining the grey clustering method and the entropy-weight method (The IGCEW method), as an extension to the qualitative and quantitative methods.

The grey clustering method enables quantification of qualitative information and classification of observed objects into definable classes, as well as verification of 
whether the observed objects belong to predetermined classes - as shown by the studies of Zhang et al. (2013), who analysed a water rights allocation system, or by Zhang et al. (2014), who classified innovation strategic alliances. It can be argued that the grey clustering method is likely to benefit the first stage of ECA in that it helps assess social impact by quantifying the qualitative information obtained from stakeholder groups involved in a given environmental conflict.

In turn, the entropy-weight method is used to calculate objective weights of criteria. If there is a large difference between the objects for a criterion determined, this criterion can be regarded as an important factor for the analysis of alternatives, as shown by the study of Wang and Lee (2009), who resolved a software selection problem, or by Kou et al. (2011), who assessed a case of environmental pollution. In our view, the entropyweight method would benefit the final stage of ECA, as it allows researchers to determine the criteria for which there is divergence between the stakeholder groups involved in a conflict. The combination of both methods would be beneficial for ECA because it integrates social impact assessment and divergent criteria identification. To illustrate the method we propose, a case study was conducted assessing the exploitation plans of a poly-metallic mine in northern Peru. Three stakeholder groups were identified and a set of seven criteria for ECA were established in the mining project.

The specific objectives of this article are to:

1. Apply the IGCEW method for ECA to the concrete context of the exploitation plans of the poly-metallic mine in Peru.

2. Explore if the IGCEW method exhibits potential for other ECA contexts.

In section 2 the literature review is described. Section 3 provides the details of the IGCEW method for ECA. In Section 4 the case study is described, followed by the results and discussion in Section 5. Conclusions are provided in Section 6.

\section{Literature review}

Environmental conflicts are characterized by the interaction between (1) ecological and (2) social complexity (Wittmer et al., 2006). 
(1) One central feature of environmental conflicts is the complexity of the ecological system which is the natural base of the conflicts. Even if its understanding is accompanied by a high degree of scientific sophistication, there remains substantial uncertainty and ignorance. Therefore, the process leading to the resolution of environmental conflicts should take into account scientific and idiosyncratic knowledge and should cope with unavoidable uncertainty and ignorance. Certain forms of multi-criteria decision aid could satisfy this demand. (Wittmer et al., 2006).

(2) Another central feature of environmental conflicts is social complexity. Some stakeholders are also actors who may impede the implementation of a decision, or, put positively, their agreement is necessary for a successful implementation of the decision. Social complexity calls for stakeholder participation. Decision structuring tools offer the possibility to make participatory decision processes more transparent (Wittmer et al., 2006).

The resolution of environmental conflicts should concentrate on both aspects, social and ecological complexity. Wittmer et al (2006) suggest approaching both aspects by an intensive integration of stakeholders and multi-criteria analysis. However, environmental conflict is a social issue and has high level of uncertainty. In addition, in classical multi-criteria analysis methods, the importance degrees of criteria and the performance scores of alternatives are assumed to be known precisely. Moreover, the practical constraints of the real world hinder the use of crisp values. The problems faced in practice occur in such an environment that the goals, constraints and consequences of alternatives are not precise. Furthermore, the ambiguities, uncertainties and vagueness inherent in decision makers' evaluations necessitate the use of methods to model uncertainty in decision problems (Baykasoglu and Gölcük, 2015). There are many methods used to model uncertainty in decision problems. Probabilistic approaches (Augustsson, et al., 2011), fuzzy logic (Zadeh, 1965), and grey systems (Liu and Lin, 2010) are some examples of the options used to model uncertainty.

The grey systems theory is a methodology for studying uncertainty problems (Deng, 1982), in which there are limited information and small samples (Liu and Lin, 2010). In order to explore the differences, we compare grey systems with other main approaches, below. 


\section{Comparison between grey systems and probabilistic approaches}

A comparison study between grey systems and probabilistic approaches was performed in 1994 by (1) Jiangping Qiu and (2) Xisheng Hua respectively, who established a theoretically delicate statistical regression model and relatively coarse grey model based on the deformation and leakage data of a certain large scale hydraulic dam. Their work shows that their grey model provided a better fit than the statistical regression model. When comparing the errors between the predictions of the two models with the actual observations, it is found that the prediction accuracy of the grey model is generally better than that of the regression model, for more details see Table 1 (Liu and Lin, 2010).

Table 1

Comparison between the prediction errors of a statistical model and a grey model.

\begin{tabular}{|c|c|c|c|}
\hline \multirow{2}{*}{$\mathrm{N}^{\mathrm{o}}$} & \multirow{2}{*}{ Type } & \multicolumn{2}{|c|}{ Average error } \\
\hline & & Statistical model & Grey model \\
\hline \multirow{3}{*}{1} & Horizontal displacement & 0.862 & 0.809 \\
\hline & Vertical displacement & 1.024 & 1.029 \\
\hline & Water level of pressure measurement hole & 6.297 & 3.842 \\
\hline \multirow{3}{*}{2} & Horizontal displacement & 0.446 & 0.232 \\
\hline & Vertical displacement & 0.465 & 0.449 \\
\hline & Water level of pressure measurement hole & 0.204 & 0.023 \\
\hline
\end{tabular}

As shown in Table 1, we believe that a model based on grey system could be more accurate than a statistical model. In addition, considering that environmental conflict is a social issue and a very inconstant and subjective topic, which requires a permanent analysis, and that one of the criteria for evaluating methods for ECA is the cost (Wittmer et al., 2006), in this aspect an approach based in grey systems would have a lower cost with respect to a statistical approach, due to the fact that sample size influences the cost of field research. 


\section{Comparison between grey systems and fuzzy logic approaches}

Fuzzy mathematics emphasizes the investigation of problems with cognitive uncertainty, where the research objects possess the characteristic of clear intention and unclear extension. For example, the instance, "young man" is a fuzzy concept, because everybody understands the idea of "young man". However, if you are going to determine the exact range within which everybody is young and outside which everybody is not young, then you will find yourself in difficulty. This is because the concept of young man does not have a clear extension. For this kind of problem of cognitive uncertainty with clear intention and unclear extension, the situation is dealt with in fuzzy mathematics by making use of experience and the so-called membership function (Liu and Lin, 2010).

The focus of grey systems theory is on the uncertainty problems of small samples and limited information which are difficult to handle for probability and fuzzy mathematics. One of its characteristics is construct models with small amounts of data. What is clearly different of fuzzy mathematics is that grey systems theory emphasizes the investigation of such objects which process clear extension and unclear intention. A summary of the differences between these approaches is shown in Table 2 (Liu and Lin, 2010).

Table 2

Comparison between grey systems and fuzzy math methods.

\begin{tabular}{lll}
\hline Object & Grey systems & Fuzzy math \\
\hline Research objects & Poor information & Cognitive uncertainty \\
Basic sets & Grey hazy sets & Fuzzy sets \\
Methods & Information coverage & Mapping \\
Procedures & Sequence operator & Cut set \\
Data requirement & Any distribution & Known membership \\
Emphasis & Clear extension & Clear intention. \\
Objective & Laws of reality & Cognitive expression \\
Characteristics & Small sample & Experience \\
\hline
\end{tabular}


Based on what is described above, we strongly believe that the grey clustering method based on grey systems could be more convenient than an approach based on fuzzy logic, to analyse an environmental conflict, due to the fact that we have clear extension and unclear intention of ECA criteria. For example, in a historic range of five years, we know the minimum and maximum value of a social variable under analysis. In addition, an affected population within a determined project is clear about when things were good or bad: before or after project implementation.

In turn, ECA should be performed considering stakeholder participation (Wittmer et al., 2006), that is, identifying and analysing divergences between stakeholder groups into the influence areas of a determined project. In addition, social impact assessment and environmental conflict prevention should be integrated (Franks and Vanclay, 2013), in order to properly manage possible environmental conflicts during project development. Stakeholders' analysis is a social topic and has a lot of uncertainty which could be dealt with by applying Shannon entropy theory. Shannon entropy is a quantitative measurement of uncertainty (Kou et al., 2011), which could help us to discern the divergence between stakeholder groups. We strongly believe the entropy-weight method, based on Shannon entropy theory, integrated with the grey clustering method, could contribute to ECA, as it integrates social impact assessment and environmental conflict prevention, in a similar way and under the same philosophy as grey systems. However, so far there has been more research on fuzzy logic or on statistics models than on grey systems or Shannon entropy, which could change to the extent that research based on grey systems or Shannon entropy proposes a further development of the theory and establishment of innovative methods in the different fields of knowledge. Based on what has been discussed above, we summarize the differences between the IGCEW method, proposed in this article, and other principal approaches in Table 3. 
Table 3

Comparison between the IGCEW method and other main approaches.

\begin{tabular}{|c|c|c|c|}
\hline Aspect & The IGCEW method & $\begin{array}{l}\text { Approaches based on } \\
\text { fuzzy logic }\end{array}$ & $\begin{array}{l}\text { Approaches based on } \\
\text { statistics }\end{array}$ \\
\hline $\begin{array}{l}\text { Epistemological } \\
\text { paradigm }\end{array}$ & $\begin{array}{l}\text { Integrate qualitative and quantitative } \\
\text { paradigms. }\end{array}$ & $\begin{array}{l}\text { Integrate qualitative and } \\
\text { quantitative paradigms. }\end{array}$ & $\begin{array}{l}\text { Prioritize quantitative } \\
\text { paradigm. }\end{array}$ \\
\hline Uncertainty & $\begin{array}{l}\text { Focus on the uncertainty problems of } \\
\text { small samples and limited } \\
\text { information. }\end{array}$ & $\begin{array}{l}\text { Investigation of problems with } \\
\text { cognitive uncertainty. }\end{array}$ & Stochastic uncertainty. \\
\hline Data requirement & Any distribution. & Known membership. & Typical distribution. \\
\hline $\begin{array}{l}\text { Emphasis of research } \\
\text { object }\end{array}$ & Clear extension and unclear intention. & $\begin{array}{l}\text { Clear intention and unclear } \\
\text { extension. }\end{array}$ & $\begin{array}{l}\text { Revealing the historical } \\
\text { statistical laws. }\end{array}$ \\
\hline $\begin{array}{l}\text { Objective of research } \\
\text { problem }\end{array}$ & Laws of reality. & Cognitive expression. & Historical statistical laws. \\
\hline $\begin{array}{l}\text { Costs during } \\
\text { application }\end{array}$ & $\begin{array}{l}\text { Low, due to the fact that a small } \\
\text { sample is used. }\end{array}$ & $\begin{array}{l}\text { Medium, due to the fact that } \\
\text { experience is used. }\end{array}$ & $\begin{array}{l}\text { High, due to the fact that a } \\
\text { large sample is used. }\end{array}$ \\
\hline
\end{tabular}

The main advantages of the IGCEW method may be summarized as follows:

(1) The grey clustering method and the entropy-weight method are combined for the first time in ECA literature.

(2) The IGCEW method is more appropriate than other classical approaches based on multi-criteria analysis, as it considers uncertainty within its analysis.

(3) The IGCEW method integrates social impact assessment and environmental conflict prevention, performing an analysis of stakeholder groups.

(4) The IGCEW method is more effective and has a lower cost than other statistical approaches during its application.

(5) The IGCEW method is more convenient than other approaches based on fuzzy logic, as it analyses environmental conflict considering clear extension of criteria for ECA.

\section{Method}

This section provides a summary of the grey clustering method and of the entropyweight method, followed by details of the IGCEW method for ECA.

\subsection{Grey clustering method based on CTWF}

The grey clustering method is based on grey system theory, originally developed by (Deng, 1985). The grey system is a theory which focuses on the study of problems involving small samples and limited information (Liu and Lin, 2010). In the real world 
there are many problems of this type, determining a broad range of applicability of the theory of grey systems, for example:

- Evaluation of web sites (Bindu et al., 2010),

- Transport management (Leng et al., 2012),

- Water management (Zhang et al., 2013),

- Safety management (Li et al., 2015, Wei et al., 2015).

The grey clustering method was developed for classifying observation indices or observation objects into definable classes using grey incidence matrices or grey whitenization weight functions. The grey clustering method using whitenization weight functions is mainly applied to test whether the objects of observation belong to predetermined classes, so that they can be treated accordingly (Liu and Lin, 2010). In this article, we use the grey clustering method based on center-point triangular whitenization weight functions (CTWF) because stakeholder groups can be treated as observation objects for ECA. In addition, since respondents tend to be more certain about the center-point of a grey class as compared with other points within the class, conclusions based on such cognitive certainty are more scientific and reliable (Liu and Lin, 2010). This fact is important for collecting information from stakeholder groups and for assessing objectively the social impact they may be affected by.

The grey clustering method based on CTWF is developed according to the following definition.

Definition 1. Assume that there are a set of $m$ objects, a set of $n$ criteria and a set of $s$ different grey classes, according to the sample value $x_{i j}(i=1,2, \ldots, m ; j=1,2, \ldots, n)$ of the $i$ th $(i=1,2, \ldots, m)$ object, for the criterion $j(j=1,2, \ldots, n)$. The steps for grey clustering based on CTWF can be expressed as follows (Liu and Lin, 2010, Zhang et al., 2014):

Step 1: The individual ranges of the criteria are divided into $s$ grey classes, and then center-points $\lambda_{1}, \lambda_{2}, \ldots, \lambda_{s}$ of grey classes $1,2, \ldots, s$ are determined.

Step 2: The grey classes are expanded in two directions, adding the grey classes 0 and $(s+1)$ with their center-points $\lambda_{0}$ and $\lambda_{s+1}$ respectively. Therefore, the new sequence of center-points is established $\lambda_{0}, \lambda_{1}, \lambda_{2}, \ldots, \lambda_{s}, \lambda_{s+1}$ (see Fig. 1). The CTWF for the $k$ th grey 
class, $k=1,2, \ldots, s$, of the $j$ th criterion, $j=1,2, \ldots, n$, for an observed value $x_{i j}$ is defined by Eq. (1).

$$
f_{j}^{k}\left(x_{i j}\right)= \begin{cases}0, & x \notin\left[\lambda_{k-1}, \lambda_{k+1}\right] \\ \frac{x-\lambda_{k-1}}{\lambda_{k}-\lambda_{k-1}}, & x \in\left[\lambda_{k-1}, \lambda_{k}\right] \\ \frac{\lambda_{k+1}-x}{\lambda_{k+1}-\lambda_{k}}, & x \in\left[\lambda_{k}, \lambda_{k+1}\right]\end{cases}
$$

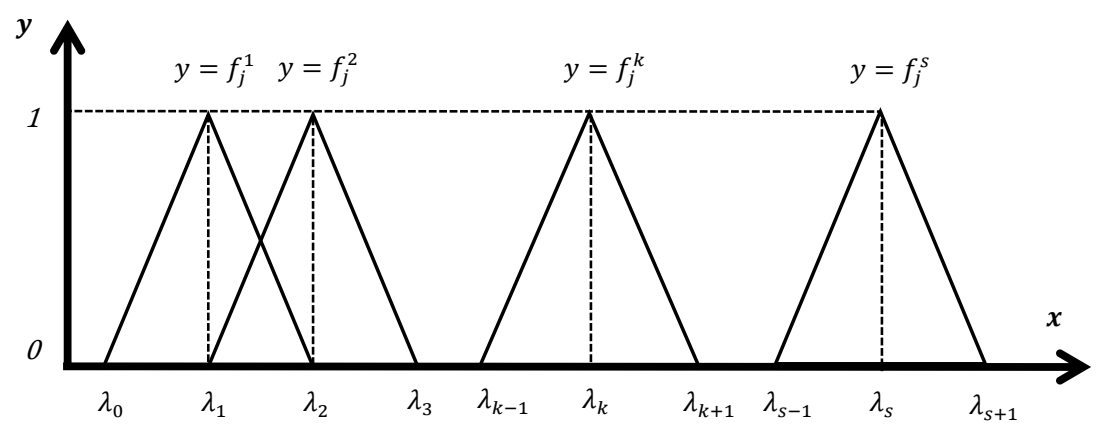

Fig. 1. Center-point triangular whitenization weight functions (CTWF).

Step 3: The comprehensive clustering coefficient $\sigma_{i}^{k}$, for object $i, i=1,2, \ldots, m$, with respect to the grey class $k, k=1, \ldots, s$ is calculated by Eq. (2).

$$
\sigma_{i}^{k}=\sum_{j=1}^{n} f_{j}^{k}\left(x_{i j}\right) \cdot \eta_{j}
$$

where $f_{j}^{k}\left(x_{i j}\right)$ is the CTWF of the $k$ th grey class of the $j$ th criterion, and $\eta_{j}$ is the weight of criterion $j$.

Step 4: If $\max _{1 \leq k \leq s}\left\{\sigma_{i}^{k}\right\}=\sigma_{i}^{k^{*}}$, we decide that object $i$ belongs to grey class $k^{*}$. When there are several objects in grey class $k^{*}$, these objects can be ordered according to the magnitudes of their comprehensive clustering coefficients.

\subsection{Entropy-weight method}

The entropy-weight method is based on Shannon entropy, originally developed by Shannon (Shannon and Weaver, 1947). Shannon entropy is a concept which is proposed as a measure of uncertainty in information, formulated in terms of probability theory. Since the concept of entropy is well suited to measuring the relative intensities of contrast criteria in order to represent the average intrinsic information transmitted for 
decision-making (Zeleny, 1996), it is an appropriate and convenient choice for our purpose. Subsequent research on Shannon entropy has contributed to the resolution of a range of problems in areas such as:

- Clinical neurophysiology (Cao and Slobounov, 2011),

- Transport systems (Chen et al., 2014),

- Environmental time series data (Srivastav and Simonovic, 2014),

- Fault detection (Heidari Bafroui and Ohadi, 2014).

Shannon developed measure $H$ which satisfies the following properties for all $p_{i}$ within an estimated joint probability distribution $P$ (Shemshadi et al., 2011, Zitnick and Kanade, 2004):

1. $H$ is a continuous positive function;

2. If all $p_{i}$ are equal, $p_{i}=1 / n$, then $H$ should be a monotonic increasing function of $n$; and,

3. For all, $n \geq 2, H\left(p_{1}, p_{2}, \ldots, p_{n}\right)=h\left(p_{1}+p_{2}, p_{3}, \ldots, p_{n}\right)+\left(p_{1}+p_{2}\right) H\left(\frac{p_{1}}{p_{1+} p_{2}}, \frac{p_{2}}{p_{1+} p_{2}}\right)$

Shannon showed that the only function which satisfies these properties is:

$$
H_{\text {Shannon }}=-\sum_{i}^{n} p_{i} \log \left(p_{i}\right)
$$

where: $\quad 0 \leq p_{i} \leq 1 ; \quad \sum_{j=1}^{n} p_{i}=1$

For a certain criterion, if there is a large difference between the alternatives, the criterion will give decision makers a large amount of information and the criterion can be regarded as an important factor (Kou et al., 2011). It can thus be argued that the entropy-weight method can be applied in ECA to determine those criteria for which there is divergence between the compared stakeholder groups.

The entropy-weight method is developed according to the following definition.

Definition 2. Assume that there are $m$ objects for evaluation and each has $n$ evaluation criteria, which form decision matrix $Z=\left\{z_{i j} ; i=1,2, \ldots, m ; j=1,2, \ldots, n\right\}$. Then, the steps of the entropy-weight method can be expressed as follows (Fagbote et al., 2014, Ji et al., 2015; Wang and Lee, 2009, Xie and Yang, 2011): 
Step 1: The decision matrix $Z=\left\{z_{i j} ; i=1,2, \ldots, m ; j=1,2, \ldots, n\right\}$ is normalized for each criterion $C j(j=1,2, \ldots, n)$. The normalized values $P_{i j}$ are calculated by Eq. (4).

$$
P_{i j}=\frac{z_{i j}}{\sum_{i=1}^{m} z_{i j}}
$$

Step 2: The entropy $H_{j}$ of each criterion $C j$ is calculated by Eq. (5).

$$
H_{j}=-k \sum_{i=1}^{m} P_{i j} \ln \left(P_{i j}\right)
$$

$\mathrm{k}$ is a constant, let $k=(\ln (m))^{-1}$.

Step 3: The degree of divergence $d i v_{j}$ of the intrinsic information in each criterion $C j$ is calculated by Eq. (6).

$$
\operatorname{div}_{j}=1-H_{j}
$$

Step 4: The entropy weight $w_{j}$ of each criterion $C j$ is calculated by Eq. (7).

$$
w_{j}=\frac{d i v_{j}}{\sum_{j=1}^{n} d i v_{j}}
$$

\subsection{Integration of the grey clustering and entropy-weight methods}

The IGCEW method for ECA combines the grey clustering method based on CTWF and the entropy-weight method, as illustrated in Fig. 2. 


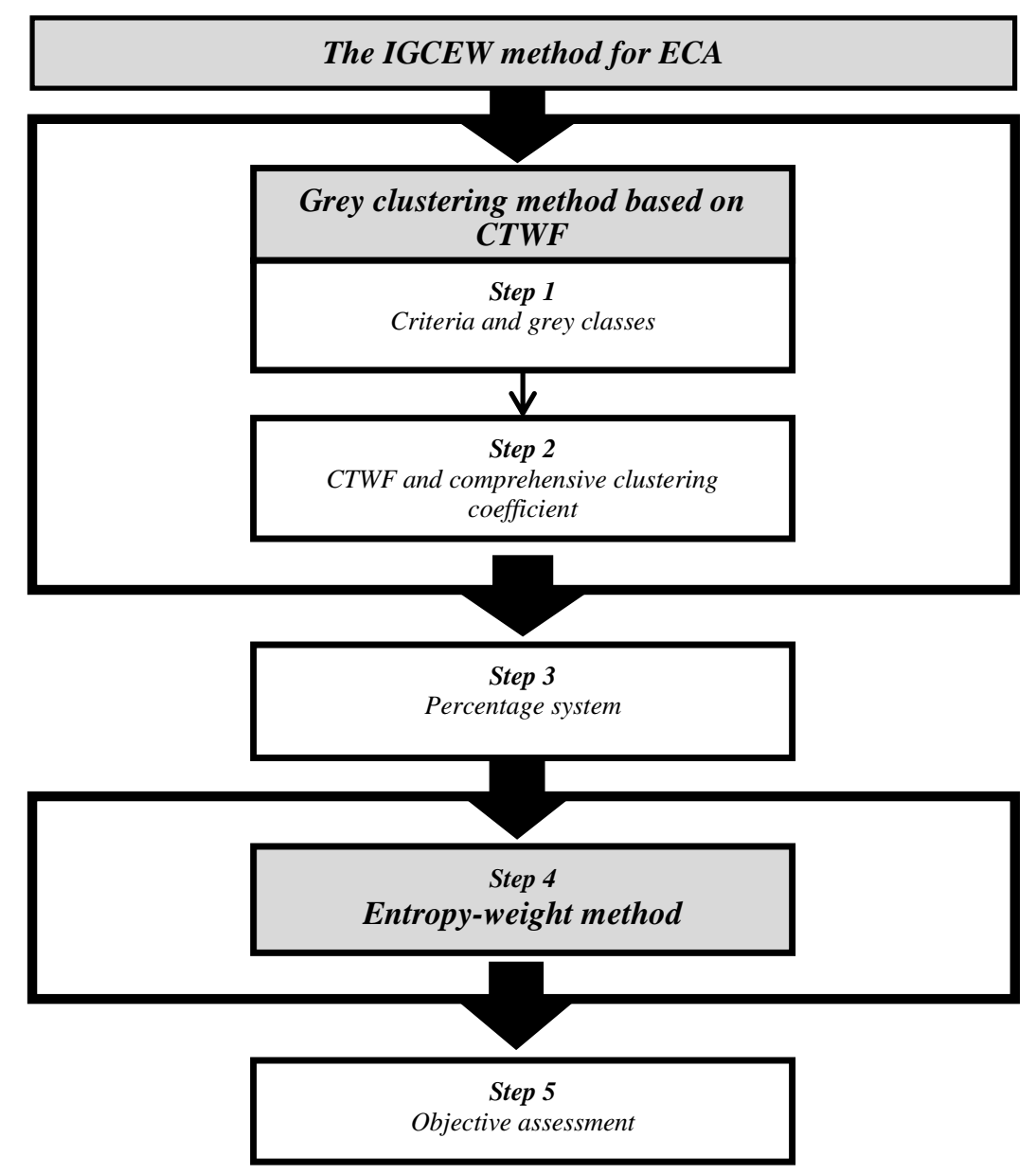

Fig. 2. Schema of the IGCEW method for ECA

The IGCEW method for ECA can be described using the following sets:

1. A set of $m$ objects or stakeholder groups called $G=\left\{G_{1}, G_{2}, \ldots, G_{m}\right\}$

2. A set of $n$ criteria called $C=\left\{C_{1}, C_{2}, \ldots, C_{n}\right\}$

3. A set of $s$ grey classes called $V=\left\{V_{l}, V_{2}, \ldots, V_{s}\right\}$

4. A set of evaluation values called $X=\left\{x_{i j}, i=1,2, \ldots, m ; j=1,2, \ldots, n\right\}$ of $G_{i}(i=1,2, \ldots, m)$ with respect to criterion $C_{j}(j=1,2, \ldots, n)$.

The steps are described below:

Step 1: Criteria and grey classes. A set of $n$ criteria and a set of $s$ grey classes for ECA are established based on the characteristics of the project under scrutiny.

Step 2: CTWF and comprehensive clustering coefficient. The values of CTWF for each stakeholder group are calculated using Eq. (1). Then, the comprehensive clustering coefficient $\boldsymbol{\sigma}_{\boldsymbol{i}}^{\boldsymbol{k}}$ for object $i, i=1,2, \ldots, m$, with respect to the grey class $k, k=1, \ldots, s$, is calculated using Eq. (2). 
Step 3: Percentage system. The social impact assessment of each stakeholder group is presented as a percentage system (Chang and Qisen, 2009), defined by values $\alpha_{1}, \alpha_{2}$, $\alpha_{3, \ldots}$, and $\alpha_{s}$, where $\alpha_{s}=100, \alpha_{1}=100 / s, \alpha_{2}=\alpha_{1}+\alpha_{1}, \alpha_{3}=\alpha_{1}+\alpha_{2}, \ldots$, and $\alpha_{s-1}=\alpha_{1}+\alpha_{s-2 ;} s$ is the number of grey classes established. The results are given by Eq. (8).

$$
z_{j}^{i}=\sum_{k=1}^{s} f_{j}^{k}\left(x_{i j}\right) \cdot \alpha_{k}
$$

where $f_{j}^{k}\left(x_{i j}\right)$ is the CTWF of the $k$ th grey class of the $j$ th criterion and $\alpha_{k}$ is the percentage value of each grey class. The results are represented by a matrix determined by Eq. (9).

$$
Z=\left\{z_{i j}, i=1,2, \ldots, m ; j=1,2, \ldots, n\right\}
$$

Step 4: Entropy-weight method. First, matrix $Z=\left\{z_{i j}, \mathbf{i}=1,2, \ldots, \mathbf{m} ; \mathbf{j}=1,2, \ldots, \mathbf{n}\right\}$ is normalized for each criterion $C j(j=1,2, \ldots, n)$. The normalized values $P_{i j}$ are calculated using Eq. (4). Then, $H_{j}$, div $v_{j}$ and $w_{j}$ are calculated using Eqs. (5), (6) and (7).

Step 5: Objective assessment. The final stage of the ECA is the calculation of objective assessment (Shemshadi et al., 2011) regarding each stakeholder group $i, i=1,2, \ldots, m$, for each criterion $C j(j=1,2, \ldots, n)$. The objective assessment value is defined by Eq. (10).

$$
Q_{i j}=w_{j} z_{i j}
$$

where $w_{j}$ is the entropy weight of each criterion $C j$ and $\mathrm{z}_{\mathrm{ij}}$ is the result of the social impact assessment for each stakeholder group $i, i=1,2, \ldots, m$. The results are represented by a matrix determined by Eq. (11).

$$
Q_{i j}=\left[\begin{array}{cccc}
w_{1} z_{11} & w_{2} z_{12} & \ldots & w_{n} z_{1 n} \\
w_{1} z_{21} & w_{2} z_{22} & \ldots & w_{n} z_{2 n} \\
\vdots & \vdots & \ddots & \vdots \\
w_{1} z_{m 1} & w_{2} z_{m 2} & \ldots & w_{n} z_{m n}
\end{array}\right]
$$

The first three steps of the IGCEW method for ECA correspond to social impact assessment, developed in accordance with the grey clustering method based on CTWF and represented by a percentage system. Then, entropy-weight and objective assessment 
are applied, which identify the criteria for which there is the greatest divergence between the stakeholder groups.

In order to illustrate and validate the IGCEW method for ECA we conducted a case study described below.

\section{Case study}

In order to test the IGCEW method, we performed an ECA of the expansion plans of a poly-metallic mine in northern Peru, in the department of Cajamarca (Fig. 3). Our study measured the social impact of this project on the zone of influence and, based on the results, determined the criteria likely to generate environmental conflicts between the identified stakeholder groups.

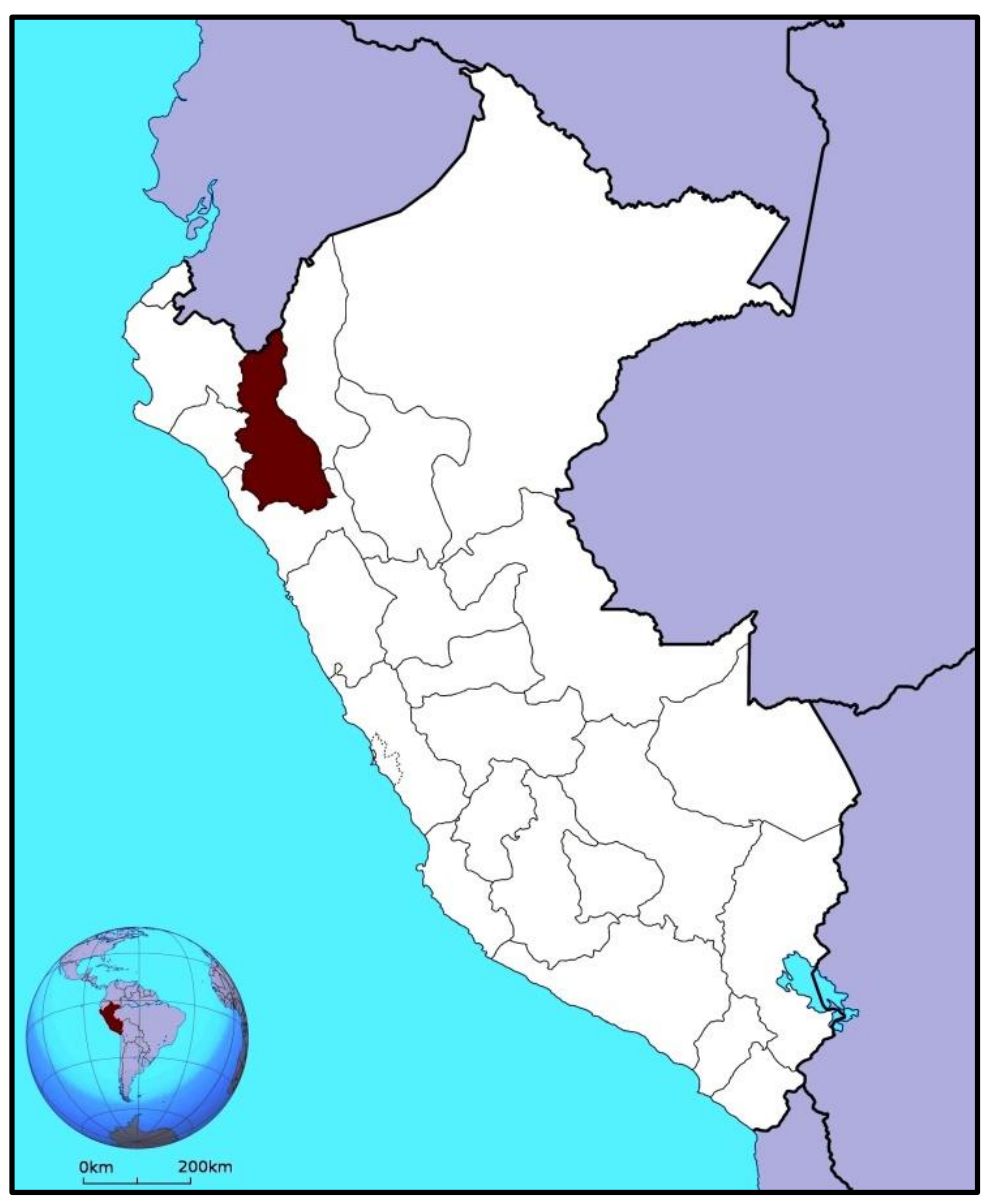

Fig. 3. Cajamarca, Peru (Wikimedia Commons, 2014). 


\subsection{Stakeholder Groups}

Our field work identified three different stakeholder groups $(k=3)$, and the composition of these groups was determined on the basis of the similarities found during the overall assessment of the expansion plans of the mine. The sample size in each group was established by the principle of saturation of discourse, which stipulates that information gathering should end when respondents no longer contribute new observations (Corbetta, 2007). The stakeholder groups were defined as follows:

\section{$G_{ı}:$ Urban population}

This group was composed of citizens from the urban areas near the exploitation site. They expressed a generally favourable opinion towards the mining project, and tended to stress the importance of private investment for the resolution of social problems. This group was made up of one hundred and fifteen interviewees.

\section{$G_{2}:$ Rural population}

This group was composed of citizens from the rural areas near the exploitation site, consisting of people undertaking productive activities related to agriculture and livestock. The group of rural population had a generally adverse opinion of the mining project and was made up of one hundred and five interviewees.

\section{$G_{3}:$ Specialists}

This group was composed of professionals from different fields who were familiar with the area of influence and the characteristics of the environmental and social impacts of the mining project, and who manifested a generally neutral assessment of the mining project. This group was made up of thirty-five interviewees.

\subsection{Calculations}

The calculations for the case study, based on the steps detailed above, proceeded as follows.

\section{Step 1: Criteria and grey classes}

The ECA criteria in the studied case were established by taking into account the economic and social situation of the area of influence and the characteristics of the evaluated mining project, as well as consultations with experts. Initially, during the exploratory study, certain criteria were submitted by stakeholders, such as unexpected 
death of livestock, lack of health facilities, subsidies for traditional celebrations in the area, and road construction. But these criteria were discarded in the analysis as they were not directly related to the project or were already covered by other previously defined criteria. Seven criteria $(n=7)$ were identified as shown in Table 4.

Table 4

ECA criteria identified in the case study.

\begin{tabular}{lll}
\hline Criterion & Code & Description \\
\hline $\begin{array}{l}\text { GDP per capita } \\
\text { Employment rate }\end{array}$ & $\mathrm{C}_{1}$ & $\begin{array}{l}\text { The GDP per capita as soles per month (annual average) in the } \\
\text { department of Cajamarca. }\end{array}$ \\
$\begin{array}{l}\text { Poverty rate } \\
\text { Number of inhabitants }\end{array}$ & $\mathrm{C}_{3}$ & $\begin{array}{l}\text { The employment rate per year in the department of Cajamarca. } \\
\text { per doctor (GP) }\end{array}$ \\
$\begin{array}{l}\text { Enrolment rate in } \\
\text { primary education } \\
\text { Number of reported } \\
\text { crimes }\end{array}$ & $\mathrm{C}_{5}$ & $\begin{array}{l}\text { The number of inhabitants per doctor (GP) per year in the } \\
\text { department of Cajamarca. }\end{array}$ \\
$\begin{array}{l}\text { Access to drinking water } \\
\text { rate }\end{array}$ & $\mathrm{C}_{6}$ & $\begin{array}{l}\text { The number of reported crimes per year in the department of } \\
\text { Cajamarca. }\end{array}$ \\
\hline
\end{tabular}

Five grey classes (Very Negative, Negative, Normal, Positive and Very Positive) were established for the mining project on the basis of historical information about the 20092013 social indicators provided by the Peru government (INEI, 2014) and a qualitative analysis of the consultations with experts - in order to satisfy the need to reflect the social impact of the specific region as accurately as possible (Liu and Lin, 2010). It was decided that the criteria had the same weight $\left(\eta_{j}=0.143\right)$, inasmuch as they were all social criteria (Corbetta, 2007). The grey classes established for each of the seven criteria are shown in Table 5. 
Table 5

Grey classes for each criterion determined in the case study.

\begin{tabular}{|c|c|c|c|c|c|}
\hline \multirow[b]{2}{*}{ Code } & \multicolumn{5}{|c|}{ Grey classes } \\
\hline & $\begin{array}{l}\text { Very } \\
\text { Negative }\left(\mathrm{V}_{1}\right) \\
\end{array}$ & Negative $\left(\mathrm{V}_{2}\right)$ & Normal $\left(\mathrm{V}_{3}\right)$ & Positive $\left(\mathrm{V}_{4}\right)$ & $\begin{array}{l}\text { Very } \\
\text { Positive }\left(V_{5}\right) \\
\end{array}$ \\
\hline $\mathrm{C}_{1}$ & $611 \leq x_{1}^{1} \leq 690$ & $690 \leq x_{1}^{2} \leq 768$ & $768 \leq x_{1}^{3} \leq 847$ & $847 \leq x_{1}^{4} \leq 926$ & $926 \leq x_{1}^{5} \leq 1004$ \\
\hline $\mathbf{C}_{2}$ & $61.8 \leq x_{2}^{1} \leq 66.2$ & $66.2 \leq x_{2}^{2} \leq 70.7$ & $70.7 \leq x_{2}^{3} \leq 75.1$ & $75.1 \leq \mathrm{x}_{2}^{4} \leq 79.6$ & $79.6 \leq x_{2}^{5} \leq 84.0$ \\
\hline $\mathbf{C}_{3}$ & $45.4 \leq x_{3}^{1} \leq 52.5$ & $38.3 \leq x_{3}^{2} \leq 45.4$ & $31.2 \leq x_{3}^{3} \leq 38.3$ & $24.1 \leq \mathrm{x}_{3}^{4} \leq 31.2$ & $17.0 \leq x_{3}^{5} \leq 24.1$ \\
\hline $\mathrm{C}_{4}$ & $2651 \leq \mathrm{x}_{4}^{1} \leq 3026$ & $2276 \leq \mathrm{x}_{4}^{2} \leq 2651$ & $1901 \leq x_{4}^{3} \leq 2276$ & $1526 \leq x_{4}^{4} \leq 1901$ & $1151 \leq x_{4}^{5} \leq 1526$ \\
\hline $\mathrm{C}_{5}$ & $93.0 \leq x_{5}^{1} \leq 93.9$ & $93.9 \leq x_{5}^{2} \leq 94.8$ & $94.8 \leq x_{5}^{3} \leq 95.7$ & $95.7 \leq x_{5}^{4} \leq 96.6$ & $96.6 \leq x_{5}^{5} \leq 97.5$ \\
\hline $\mathrm{C}_{6}$ & $7651 \leq \mathrm{x}_{6}^{1} \leq 9075$ & $6226 \leq x_{6}^{2} \leq 7651$ & $4802 \leq x_{6}^{3} \leq 6226$ & $3377 \leq x_{6}^{4} \leq 4802$ & $1953 \leq x_{6}^{5} \leq 3377$ \\
\hline $\mathbf{C}_{7}$ & $55.1 \leq \mathrm{x}_{7}^{1} \leq 61.8$ & $61.8 \leq x_{7}^{2} \leq 68.5$ & $68.5 \leq x_{7}^{3} \leq 75.2$ & $75.2 \leq x_{7}^{4} \leq 81.9$ & $81.9 \leq x_{7}^{5} \leq 88.6$ \\
\hline
\end{tabular}

\section{Step 2: CTWF and the comprehensive clustering coefficient}

The data obtained from the stakeholder groups were evaluated using CTWF. The grey classes were extended in two directions by adding classes $V_{0}$ and $V_{6}$ ("extra negative" and "extra positive", respectively), and their center-points $\lambda_{0}$ and $\lambda_{6}$ were determined. Therefore, there was a new sequence of center-points, $\lambda_{0}, \lambda_{1}, \lambda_{2}, \lambda_{3}, \lambda_{4}, \lambda_{5}$ and $\lambda_{6}$, as shown in Table 6 and Fig. 4.

Table 6

Center-points of the extended grey classes obtained in the case study.

\begin{tabular}{llllllll}
\hline \multirow{2}{*}{ Criteria } & \multicolumn{7}{c}{ Center-points of the extended grey classes } \\
\cline { 2 - 7 } & $\begin{array}{l}\text { Extra Negative } \\
\text { impact }\left(\lambda_{0}\right)\end{array}$ & $\begin{array}{l}\text { Very Negative } \\
\text { impact }\left(\lambda_{1}\right)\end{array}$ & $\begin{array}{l}\text { Negative } \\
\text { impact }\left(\lambda_{2}\right)\end{array}$ & $\begin{array}{l}\text { Normal } \\
\text { impact }\left(\lambda_{3}\right)\end{array}$ & $\begin{array}{l}\text { Positive } \\
\text { impact }\left(\lambda_{4}\right)\end{array}$ & $\begin{array}{l}\text { Very Positive } \\
\text { impact }\left(\lambda_{5}\right)\end{array}$ & $\begin{array}{l}\text { Extra Positive } \\
\text { impact }\left(\lambda_{6}\right)\end{array}$ \\
\hline $\mathbf{C}_{\mathbf{1}}$ & 572 & 651 & 729 & 808 & 886 & 965 & 1044 \\
$\mathbf{C}_{\mathbf{2}}$ & 59.6 & 64.0 & 68.5 & 72.9 & 77.4 & 81.8 & 86.3 \\
$\mathbf{C}_{\mathbf{3}}$ & 56.0 & 48.9 & 41.8 & 34.7 & 27.6 & 20.5 & 13.4 \\
$\mathbf{C}_{\mathbf{4}}$ & 3213 & 2838 & 2463 & 2088 & 1713 & 1338 & 963 \\
$\mathbf{C}_{\mathbf{5}}$ & 92.5 & 93.4 & 94.3 & 95.2 & 96.1 & 97.0 & 97.9 \\
$\mathbf{C}_{\mathbf{6}}$ & 9788 & 8363 & 6939 & 5514 & 4090 & 2665 & 1241 \\
$\mathbf{C}_{7}$ & 51.7 & 58.4 & 65.1 & 71.8 & 78.5 & 85.2 & 91.9 \\
\hline
\end{tabular}




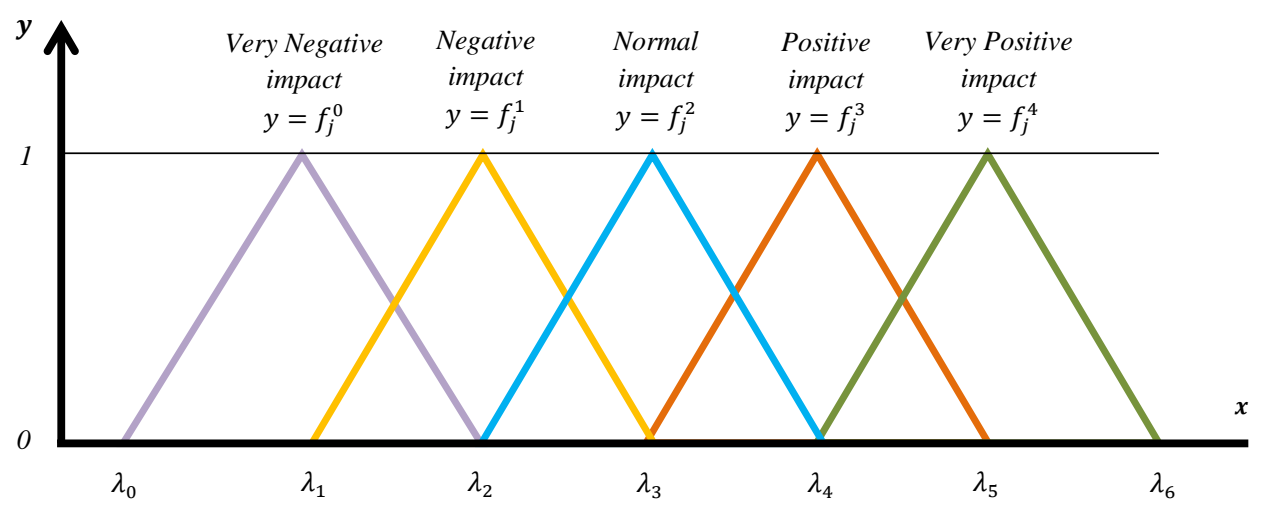

Fig. 4. CTWF in the case study.

To illustrate, for the first criterion $C_{l}(j=1)$, shown in the first row of Table 2 and Table 3 , we first had the grey classes $V_{1}=[611 ; 690], V_{2}=[690 ; 768], V_{3}=[768 ; 847], V_{4}=$ [847; 926], and $V_{5}=[926 ; 1004]$, with their center-points being $\lambda_{1}=651, \lambda_{2}=729$, $\lambda_{3}=808, \lambda_{4}=886$ and $\lambda_{5}=965$. The grey classes were then expanded in two directions by adding the grey classes $V_{0}=[533 ; 611]$ and $V_{6}=[1004 ; 1083]$, with their center-points being $\lambda_{0}=572$ and $\lambda_{6}=1044$. Thus, we obtained a new sequence of center-points: $\lambda_{0}, \lambda_{1}$, $\lambda_{2}, \lambda_{3}, \lambda_{4}, \lambda_{5}$ and $\lambda_{6}$. The values were substituted into Eq. (1), and the CTWF of the five grey classes were then obtained. The results for the first criterion $C_{j}(j=1)$ are shown in Eqs. (12), (13), (14), (15) and (16):

$$
\begin{aligned}
& f_{1}^{1}(x)= \begin{cases}\frac{0,}{x-572} & x \notin[572,729] \\
\frac{729-x}{78}, & x \in[572,651]\end{cases} \\
& f_{1}^{2}(x)= \begin{cases}\frac{x-651}{78}, & x \in[651,729] \\
\frac{808-x}{79}, & x \in[651,729]\end{cases} \\
& f_{1}^{3}(x)= \begin{cases}\frac{0,}{0,} & x \notin[729,808] \\
\frac{x-729}{79}, & x \in[729,808] \\
\frac{886-x}{78}, & x \in[808,886]\end{cases}
\end{aligned}
$$




$$
\begin{aligned}
& f_{1}^{4}(x)= \begin{cases}\frac{x-808}{78}, & x \notin[808,965] \\
\frac{965-x}{79}, & x \in[808,886]\end{cases} \\
& f_{1}^{5}(x)= \begin{cases}\frac{x-886,965]}{79}, & x \notin[886,1044] \\
\frac{x-1044-x}{79}, & x \in[965,1044]\end{cases}
\end{aligned}
$$

The data was collated by means of a field study carried out in the area of influence of the mining project. The information from the stakeholder groups was gathered via direct interviews using a structured questionnaire based on the evaluation criteria and the grey classes established. The questions used in the questionnaire are presented in Table 7.

\section{Table 7}

\begin{tabular}{|c|c|c|c|c|c|c|}
\hline \multirow{2}{*}{\multicolumn{2}{|c|}{ Question }} & \multicolumn{5}{|c|}{ Grey classes } \\
\hline & & \multirow{3}{*}{$\begin{array}{c}\begin{array}{c}\text { Very Negative } \\
\text { (V1) }\end{array} \\
\text { Decrease } \\
\text { noticeably } \\
\end{array}$} & \multirow{3}{*}{$\begin{array}{c}\begin{array}{c}\text { Negative } \\
\text { (V2) }\end{array} \\
\text { Decrease }\end{array}$} & \multirow{3}{*}{$\begin{array}{c}\begin{array}{c}\text { Normal } \\
\text { (V3) }\end{array} \\
\text { No effect }\end{array}$} & \multirow{3}{*}{$\begin{array}{c}\begin{array}{c}\text { Positive } \\
\text { (V4) }\end{array} \\
\text { Increase }\end{array}$} & \multirow{3}{*}{$\begin{array}{c}\begin{array}{l}\text { Very Positive } \\
\text { (V5) }\end{array} \\
\begin{array}{c}\text { Increase } \\
\text { noticeably }\end{array} \\
\end{array}$} \\
\hline 1 & What effect would the project have on the & & & & & \\
\hline 1 & & & & & & \\
\hline \multirow{2}{*}{2} & \multirow{2}{*}{$\begin{array}{l}\text { What effect would the project have on the } \\
\text { employment rate? }\end{array}$} & $\begin{array}{c}\text { Decrease } \\
\text { noticeably }\end{array}$ & Decrease & No effect & Increase & $\begin{array}{c}\text { Increase } \\
\text { noticeably }\end{array}$ \\
\hline & & & & & & \\
\hline \multirow{2}{*}{3} & \multirow{2}{*}{$\begin{array}{l}\text { What effect would the project have on the poverty } \\
\text { rate? }\end{array}$} & $\begin{array}{c}\text { Increase } \\
\text { noticeably }\end{array}$ & Increase & No effect & Decrease & $\begin{array}{c}\text { Decrease } \\
\text { noticeably }\end{array}$ \\
\hline & & & & & & \\
\hline \multirow{2}{*}{4} & \multirow{2}{*}{$\begin{array}{l}\text { What effect would the project have on the number } \\
\text { of inhabitants per doctor (GP)? }\end{array}$} & $\begin{array}{c}\text { Increase } \\
\text { noticeably }\end{array}$ & Increase & No effect & Decrease & $\begin{array}{c}\text { Decrease } \\
\text { noticeably }\end{array}$ \\
\hline & & & & & & \\
\hline \multirow{2}{*}{5} & \multirow{2}{*}{$\begin{array}{l}\text { What effect would the project have on the } \\
\text { enrolment rate in primary education? }\end{array}$} & $\begin{array}{c}\text { Decrease } \\
\text { noticeably }\end{array}$ & Decrease & No effect & Increase & $\begin{array}{c}\text { Increase } \\
\text { noticeably }\end{array}$ \\
\hline & & & & & & \\
\hline \multirow{2}{*}{6} & \multirow{2}{*}{$\begin{array}{l}\text { What effect would the project have on the number } \\
\text { of reported crimes? }\end{array}$} & $\begin{array}{c}\text { Increase } \\
\text { noticeably }\end{array}$ & Increase & No effect & Decrease & $\begin{array}{c}\text { Decrease } \\
\text { noticeably }\end{array}$ \\
\hline & & & & & & \\
\hline \multirow{2}{*}{7} & \multirow{2}{*}{$\begin{array}{l}\text { What effect would the project have on the access } \\
\text { to drinking water? }\end{array}$} & $\begin{array}{c}\text { Decrease } \\
\text { noticeably }\end{array}$ & Decrease & No effect & Increase & $\begin{array}{c}\text { Increase } \\
\text { noticeably }\end{array}$ \\
\hline & & & & & & \\
\hline
\end{tabular}

Questions used in the questionnaire. 
Table 8 shows the overall results of the evaluation of the three stakeholder groups $(m=$ 3) with respect to each criterion. The data were aggregated using arithmetic means (Aznar and Guijarro, 2012).

Table 8

Aggregated values for each criterion for groups $G_{l}, G_{2}$ and $G_{3}$.

\begin{tabular}{llllllll}
\hline Group & $\mathrm{C}_{1}$ & $\mathrm{C}_{2}$ & $\mathrm{C}_{3}$ & $\mathrm{C}_{4}$ & $\mathrm{C}_{5}$ & $\mathrm{C}_{6}$ & $\mathrm{C}_{7}$ \\
\hline $\mathbf{G}_{\mathbf{1}}$ & 929 & 80.3 & 23 & 1777 & 95.9 & 4578 & 83 \\
$\mathbf{G}_{\mathbf{2}}$ & 689 & 67.6 & 45 & 2324 & 94.7 & 6369 & 60 \\
$\mathbf{G}_{\mathbf{3}}$ & 902 & 78.2 & 29 & 1788 & 95.2 & 5799 & 69 \\
\hline
\end{tabular}

By way of illustration, for group $G_{l}$ the values of CTWF were calculated using Eqs. (12), (13), (14), (15) and (16). Subsequently, the comprehensive clustering coefficient $\left(\boldsymbol{\sigma}_{\boldsymbol{i}}^{\boldsymbol{k}}\right)$ was calculated for each stakeholder group using Eq. (2). The values of CTWF and $\boldsymbol{\sigma}_{\boldsymbol{i}}^{\boldsymbol{k}}$ obtained for group $G_{1}(m=1)$ are shown in Table 9.

Table 9

Values of CTWF and $\boldsymbol{\sigma}_{i}^{k}$ for group $G_{l}$.

\begin{tabular}{lllllllll}
\hline $\boldsymbol{f}_{\boldsymbol{j}}^{\boldsymbol{k}}(\boldsymbol{x})$ & $\mathrm{C}_{1}$ & $\mathrm{C}_{2}$ & $\mathrm{C}_{3}$ & $\mathrm{C}_{4}$ & $\mathrm{C}_{5}$ & $\mathrm{C}_{6}$ & $\mathrm{C}_{7}$ & $\boldsymbol{\sigma}_{\boldsymbol{i}}^{\boldsymbol{k}}$ \\
\hline $\boldsymbol{f}_{\boldsymbol{j}}^{\mathbf{1}}(\boldsymbol{x})$ & 0.00 & 0.00 & 0.00 & 0.00 & 0.00 & 0.00 & 0.00 & 0.00 \\
$\boldsymbol{f}_{\boldsymbol{j}}^{\boldsymbol{2}}(\boldsymbol{x})$ & 0.00 & 0.00 & 0.00 & 0.00 & 0.00 & 0.00 & 0.00 & 0.00 \\
$\boldsymbol{f}_{\boldsymbol{j}}^{\mathbf{3}}(\boldsymbol{x})$ & 0.00 & 0.00 & 0.00 & 0.17 & 0.23 & 0.34 & 0.00 & 0.11 \\
$\boldsymbol{f}_{\boldsymbol{j}}^{\mathbf{4}}(\boldsymbol{x})$ & 0.46 & 0.34 & 0.31 & 0.83 & 0.77 & 0.66 & 0.29 & 0.52 \\
$\boldsymbol{f}_{\boldsymbol{j}}^{\mathbf{5}}(\boldsymbol{x})$ & 0.54 & 0.66 & 0.69 & 0.00 & 0.00 & 0.00 & 0.71 & 0.37 \\
\hline
\end{tabular}

Identical procedure was applied to the other groups in the case study.

\section{Step 3: Percentage system}

The social impact assessment for the case study was presented as a percentage system, defined by values $\alpha_{1}, \alpha_{2}, \alpha_{3}, \alpha_{4}$, and $\alpha_{5}$, where $\alpha_{5}=100, \alpha_{1}=100 / 5=20, \alpha_{2}=\alpha_{1}+\alpha_{1}=40$, $\alpha_{3}=\alpha_{1}+\alpha_{2}=60$ and $\alpha_{4}=\alpha_{1}+\alpha_{3}=80$, according to the grey classes established $(s=5)$. The results are given in Table 10. To illustrate, the values of social impact assessment for group $G_{l}$ were calculated using Eq. (8), as shown in Table 11. 
Table 10

The percentage system established in the case study.

\begin{tabular}{lll}
\hline Social impact class & Interval & $\alpha_{\mathrm{k}}$ \\
\hline Very negative & {$[20,30]$} & 20 \\
Negative & {$[30,50]$} & 40 \\
Normal & {$[50,70]$} & 60 \\
Positive & {$[70,90]$} & 80 \\
Very positive & {$[90,100]$} & 100 \\
\hline
\end{tabular}

Table 11

Social impact assessment for group $G_{l}$.

\begin{tabular}{llllllllll}
\hline $\begin{array}{l}\text { Impact } \\
\text { class }\end{array}$ & $\alpha_{k}$ & $\mathrm{C}_{1}$ & $\mathrm{C}_{2}$ & $\mathrm{C}_{3}$ & $\mathrm{C}_{4}$ & $\mathrm{C}_{5}$ & $\mathrm{C}_{6}$ & $\mathrm{C}_{7}$ & Total \\
\hline $\begin{array}{l}\text { Very } \\
\text { negative }\end{array}$ & 20 & 0.00 & 0.00 & 0.00 & 0.00 & 0.00 & 0.00 & 0.00 & 0.00 \\
Negative & 40 & 0.00 & 0.00 & 0.00 & 0.00 & 0.00 & 0.00 & 0.00 & 0.00 \\
Normal & 60 & 0.00 & 0.00 & 0.00 & 10.29 & 13.71 & 20.57 & 0.00 & 6.37 \\
$\begin{array}{l}\text { Positive } \\
\text { Very }\end{array}$ & 80 & 36.57 & 27.43 & 25.14 & 66.29 & 61.71 & 52.57 & 22.86 & 41.80 \\
positive & 100 & 54.29 & 65.71 & 68.57 & 0.00 & 0.00 & 0.00 & 71.43 & 37.14 \\
\cline { 2 - 9 } & & 90.86 & 93.14 & 93.71 & 76.57 & 75.43 & 73.14 & 94.29 & 85.31 \\
\cline { 2 - 9 } & & $\begin{array}{l}\text { Very } \\
\text { positive }\end{array}$ & $\begin{array}{l}\text { Very } \\
\text { positive }\end{array}$ & $\begin{array}{l}\text { Very } \\
\text { positive }\end{array}$ & Positive & Positive & Positive & $\begin{array}{l}\text { Very } \\
\text { positive }\end{array}$ & Positive \\
\hline
\end{tabular}

The values of social impact assessment for groups $G_{2}$ and $G_{3}$ were obtained using the same procedure as for group $G_{l}$. A complete summary of all the results is shown in Table 12 .

Table 12

Social impact assessment for groups $G_{1}, G_{2}$ and $G_{3}$.

\begin{tabular}{llllllllll}
\hline Group & $\mathrm{C}_{1}$ & $\mathrm{C}_{2}$ & $\mathrm{C}_{3}$ & $\mathrm{C}_{4}$ & $\mathrm{C}_{5}$ & $\mathrm{C}_{6}$ & $\mathrm{C}_{7}$ & Total & Impact class \\
\hline $\mathbf{G}_{\mathbf{1}}$ & 90.86 & 93.14 & 93.71 & 76.57 & 75.43 & 73.14 & 94.29 & 85.31 & Positive impact \\
$\mathbf{G}_{\mathbf{2}}$ & 29.71 & 36.00 & 29.71 & 47.43 & 48.00 & 48.00 & 25.71 & 37.80 & Negative impact \\
$\mathbf{G}_{\mathbf{3}}$ & 84.00 & 84.00 & 76.00 & 76.00 & 60.00 & 56.00 & 52.00 & 69.71 & Normal impact \\
\hline
\end{tabular}

\section{Step 4: Entropy-weight method}

We next proceeded to apply the entropy-weight method part. First, the criteria values shown in Table 12 were normalized using Eq. (4), the normalized values are given in Table 13. Then, $H_{j}$, div $v_{j}$ and $w_{j}$ were calculated using Eqs. (5), (6) and (7). The results are given in Table 14. 
Table 13

Normalized values of social impact assessment for groups $G_{l}, G_{2}$ and $G_{3}$.

\begin{tabular}{llllllll}
\hline Group & $\mathrm{C}_{1}$ & $\mathrm{C}_{2}$ & $\mathrm{C}_{3}$ & $\mathrm{C}_{4}$ & $\mathrm{C}_{5}$ & $\mathrm{C}_{6}$ & $\mathrm{C}_{7}$ \\
\hline $\mathbf{G}_{\mathbf{1}}$ & 0.44 & 0.44 & 0.47 & 0.38 & 0.41 & 0.41 & 0.55 \\
$\mathbf{G}_{\mathbf{2}}$ & 0.15 & 0.17 & 0.15 & 0.24 & 0.26 & 0.27 & 0.15 \\
$\mathbf{G}_{\mathbf{3}}$ & 0.41 & 0.39 & 0.38 & 0.38 & 0.33 & 0.32 & 0.30 \\
\hline
\end{tabular}

Table 14

Values of $H j$, divj and $w j$ for each criterion in the case study.

\begin{tabular}{llllllll}
\hline & $\mathrm{C}_{1}$ & $\mathrm{C}_{2}$ & $\mathrm{C}_{3}$ & $\mathrm{C}_{4}$ & $\mathrm{C}_{5}$ & $\mathrm{C}_{6}$ & $\mathrm{C}_{7}$ \\
\hline $\boldsymbol{H}_{\boldsymbol{j}}$ & 0.92 & 0.94 & 0.92 & 0.98 & 0.98 & 0.99 & 0.89 \\
$\boldsymbol{d i v}_{\boldsymbol{j}}$ & 0.08 & 0.06 & 0.08 & 0.02 & 0.02 & 0.01 & 0.11 \\
$\boldsymbol{w}_{\boldsymbol{j}}$ & 0.21 & 0.16 & 0.21 & 0.05 & 0.04 & 0.04 & 0.29 \\
\hline
\end{tabular}

\section{Step 5: Objective assessment}

The ECA was completed by calculating objective assessment for each stakeholder group $i, i=1,2,3$, for each criterion $C j(j=1,2,3,4,5,6,7)$, using Eq. (10). The results are shown in Table 15.

Table 15

Objective assessment scores for each group in the case study.

\begin{tabular}{llllllll}
\hline Group & $\mathrm{C}_{1}$ & $\mathrm{C}_{2}$ & $\mathrm{C}_{3}$ & $\mathrm{C}_{4}$ & $\mathrm{C}_{5}$ & $\mathrm{C}_{6}$ & $\mathrm{C}_{7}$ \\
\hline $\mathbf{G}_{\mathbf{1}}$ & 19.43 & 14.98 & 20.05 & 3.91 & 2.94 & 2.63 & 26.90 \\
$\mathbf{G}_{\mathbf{2}}$ & 6.36 & 5.79 & 6.36 & 2.42 & 1.87 & 1.72 & 7.34 \\
$\mathbf{G}_{\mathbf{3}}$ & 17.97 & 13.51 & 16.26 & 3.88 & 2.34 & 2.01 & 14.84 \\
\hline
\end{tabular}

\section{Results and Discussion}

The results and discussion are presented below in accordance with the two main objectives of this article.

\subsection{The case study}

The detailed calculations for the case study produced three important findings, which we discuss below.

First, the IGCEW method helped to identify major tensions among the stakeholder groups. Fig. 5 (based on Table 12) shows the score of social impact assessment for each stakeholder group: for group $G_{1}$ (urban population) the score was 85.31 (positive impact), for group $G_{2}$ (rural population) it was 37.80 (negative impact) and for group $G_{3}$ 
(specialists) it was 69.71 (normal impact). These results suggest a strong antagonism between groups $G_{1}$ and $G_{2}$, despite the specialists $\left(G_{3}\right)$ expressing the opinion that the mining project would have an acceptable degree of social impact. The results for $G_{3}$ indicate that the mining project would not generate dramatic social problems, but the directly affected populations, as represented by groups $G_{1}$ and $G_{2}$, presented contradictory views of the project, the difference suggesting potential conflicts between $G_{1}$ and $G_{2}$ groups. In order to analyse and more fully understand the mechanisms and forces at play, we need to look at the specific criteria of conflict between $G_{1}$ and $G_{2}$, which points to our second important finding.

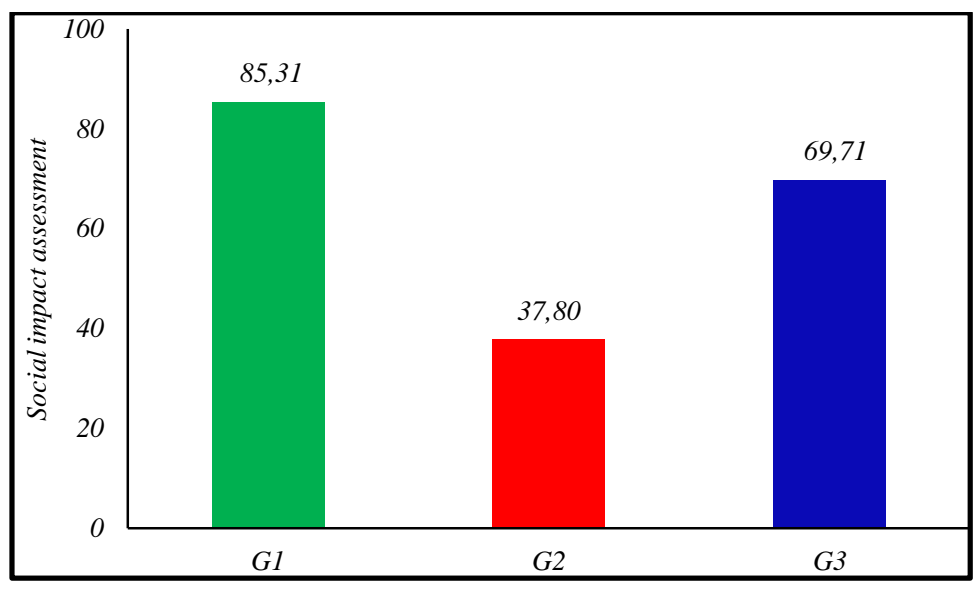

Fig. 5. Total social impact assessment of $G_{1}, G_{2}$ and $G_{3}$.

The second interesting finding in our case study analysis is that the behaviour of the criteria is considerably different across the affected groups. Fig. 6, derived from Table 12 , shows the results of social impact assessment for each criterion. For group $G_{1}$, the criteria $C_{1}, C_{2}, C_{3}$ and $C_{7}$ are placed in the range of "very positive impact" (90-100), and the criteria $C_{1}, C_{5}$ and $C_{6}$ occur in the range of "positive impact" (70-90). In addition, for group $G_{2}$, the criteria $C_{1}, C_{3}$ and $C_{7}$ are found in the range of "very negative impact" (20-30), and the criteria $C_{2}, C_{4}, C_{5}$ and $C_{6}$ in the range of "negative impact" (30-50). These results pose a need for a closer comparison of all these criteria in order to identify the most controversial ones among them. 


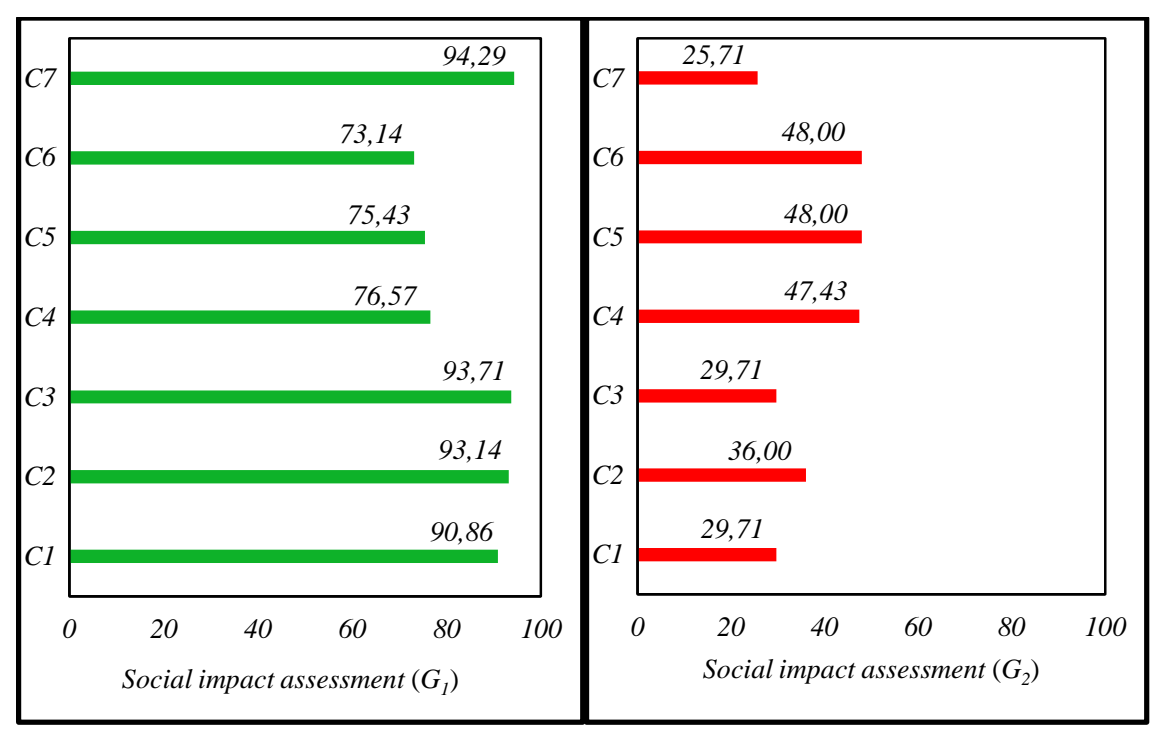

Fig. 6. Social impact assessment for each criterion for groups $G_{l}$ and $G_{2}$.

It is at this stage that our third finding and the entropy-weight method proved useful. We were able to identify the most divergent criteria implying the most potential causes of conflict between the affected stakeholder groups. Fig. 7, based on Table 15, shows that the stakeholder groups converge for criteria $C_{4}$ (number of inhabitants per doctor (GP)), $C_{5}$ (Enrolment rate in primary education) and $C_{6}$ (number of reported crimes), while they diverge for criteria $C_{1}$ (GDP per capita), $C_{2}$ (employment rate), $C_{3}$ (poverty rate) and $C_{7}$ (access to drinking water rate). The criteria with the greatest divergence are related to access to drinking water, poverty, GDP per capita and employment, in that order. It would thus appear that these four issues should first be taken into account when implementing measures to prevent environmental conflict over the mining project analysed. In addition, Fig. 7 also shows that the criterion with the greatest divergence is related to access to drinking water $\left(C_{7}\right)$. This very issue is especially problematic due to $G_{2}$ 's strongly expressed belief that the mining company's planned activity would contribute greatly to the contamination of the water sources. 


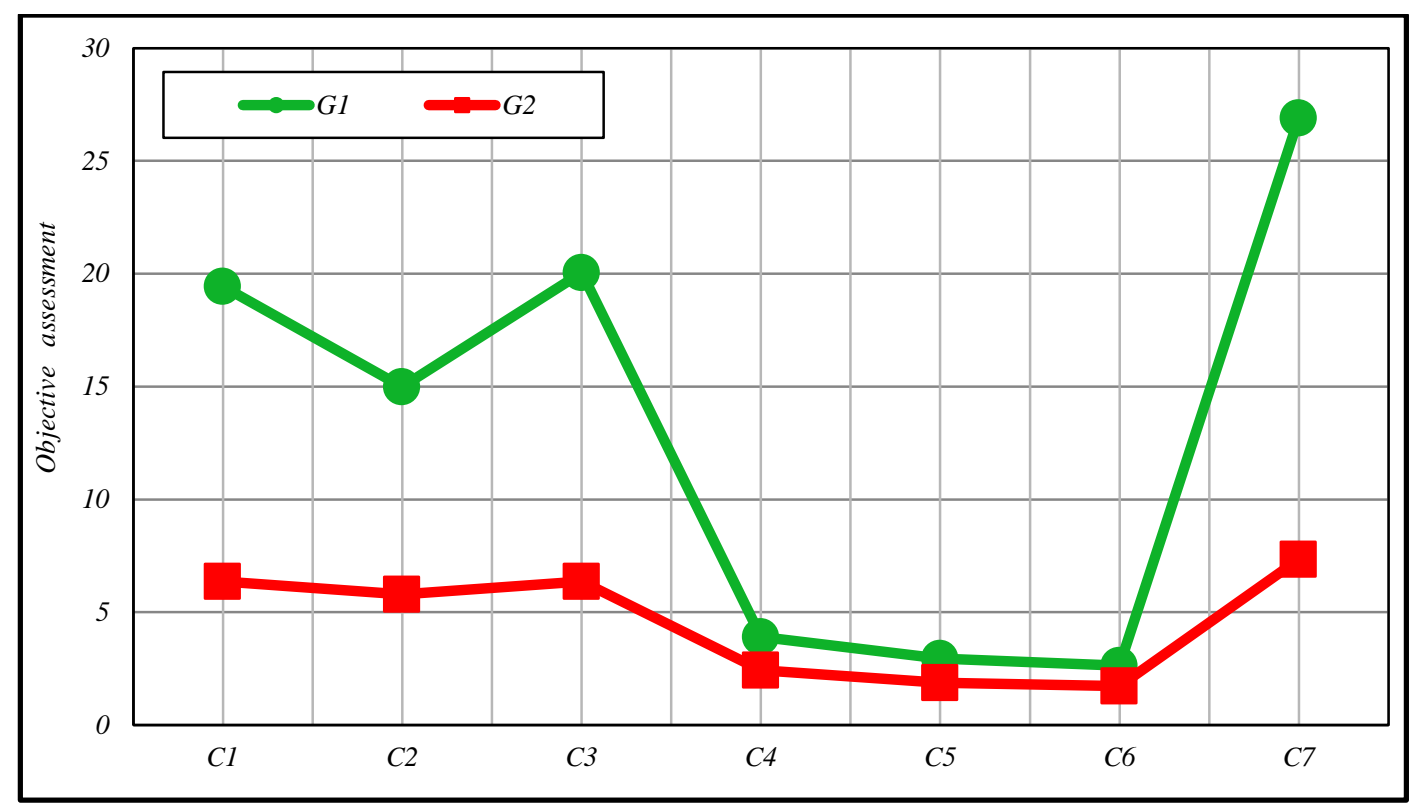

Fig. 7. Objective assessment for each criterion for groups $G_{1}$ and $G_{2}$.

\subsubsection{Sensitivity Analysis}

The IGCEW method is flexible, versatile and adjustable due to the fact that the number of stakeholder groups and number of ECA criteria are determined according to the particularities of the project under scrutiny. In the case studied in this article, we determined seven criteria and three stakeholder groups.

The IGCEW method is sensitive to number and type of stakeholder groups. For example, in our case study, if we were to include the environmental advocacy stakeholder group, see Fig. 8, the mining project would have very negative total impact, as in the opinion of this stakeholder group the mining project is completely non-viable (Sánchez, 2011). If we were to include the government stakeholder group or the company stakeholder group the mining project would have very positive total impact, as in the opinion of these stakeholder groups the mining project is completely viable (Knight Piésold, 2010, MINAN, 2011). In this study, we excluded the environmental advocacy, government and company stakeholder groups, as these stakeholders groups distort the results; in addition, they are not the directly affected population (Wittmer et al., 2006). 


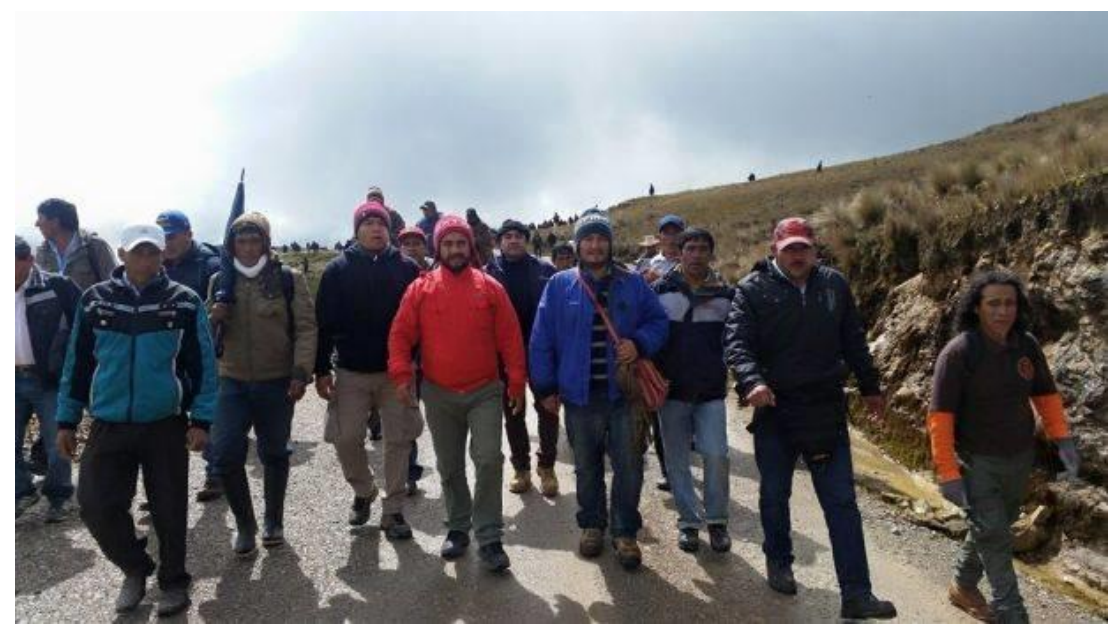

Fig. 8. Environmental advocacy stakeholder group (El Comercio, 2015)

\subsubsection{Analysis of diverging criteria}

The mining project, commonly called Conga, consists of Newmont Mining Corporation (51.35\%), Compañía de Minas Buenaventura (43.65\%), and the World Bank's International Finance Corporation (5\%). The planned duration of the mining process is 19 years, including 2 years of construction and 17 years in operation. The standard annual operation consists of the removal of overburden (topsoil and rocks) in order to obtain low-grade metal ores, which are then concentrated using a combination of physical and chemical processes that entail the very intense use of water (Silva-Macher and Farrel, 2014 ).

In order to establish some measures to prevent environment conflict in the mining project, we analyse the context of the diverging criteria below.

\section{Access to drinking water}

Access to drinking water is the most controversial criterion, in terms of the quantity and quality of the water supply to rural and urban areas. The mining project is placed at the headwaters of five important watersheds. In addition, the mining company plans to use four natural lagoons, the lagoon El Perol among them, see Fig. 9. These lagoons will be emptied, the first two for mineralogical use and the last two for waste rock dumps (MINAM, 2011). The mining company proposes building four water reservoirs, enough to replace the volumes of the natural lagoons and satisfy the demands of rural and urban areas (Knight Piésold, 2010). 


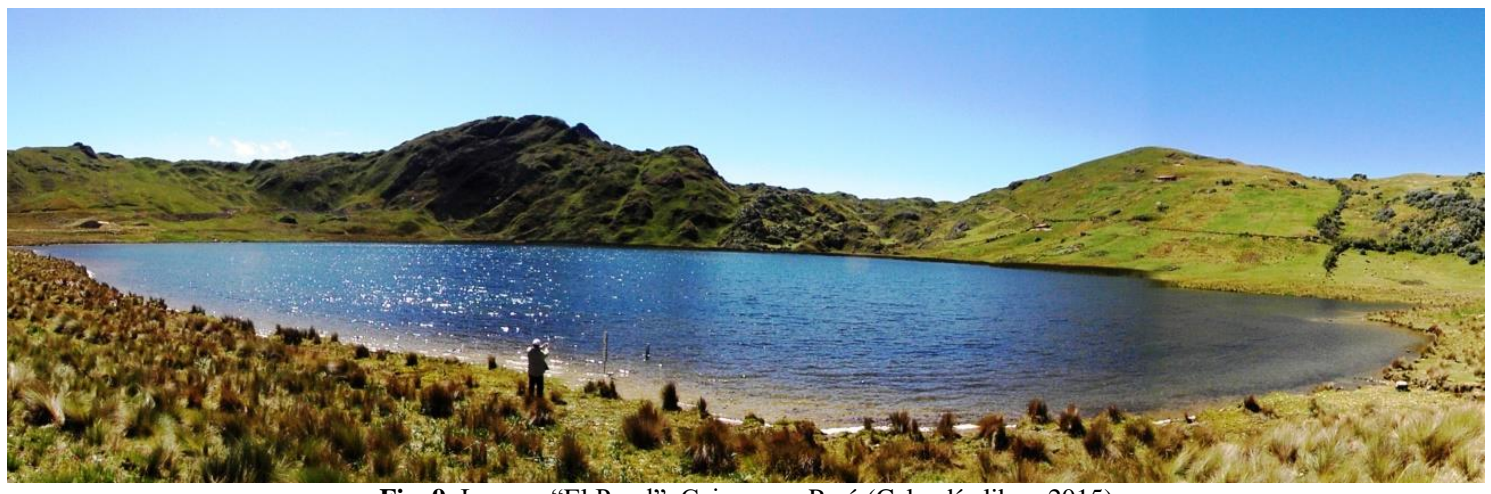

Fig. 9. Lagoon "El Perol”, Cajamarca-Perú (Celendín libre, 2015)

On the one hand, the urban stakeholder group strongly believes that there will be no problems with the quality and quantity of water for urban areas and the economic benefits to the city will be much more advantageous. On the other hand, the rural stakeholder group strongly believes that there will be problems with the quality and quantity of water for rural areas, as the mining company has caused serious environmental damage in previous projects developed in the area (Grufides, 2015), see Fig. 10. In addition, the mining company conducted an environmental impact assessment (EIA) in 2010 (Knight Piésold, 2010), in order to show the viability of the project. However, the rural stakeholder group believes that it is not transparent, as the mining company hired a consulting company to conduct the EIA, even though this is permitted by Peruvian law. This perception was present in all controversial criteria.

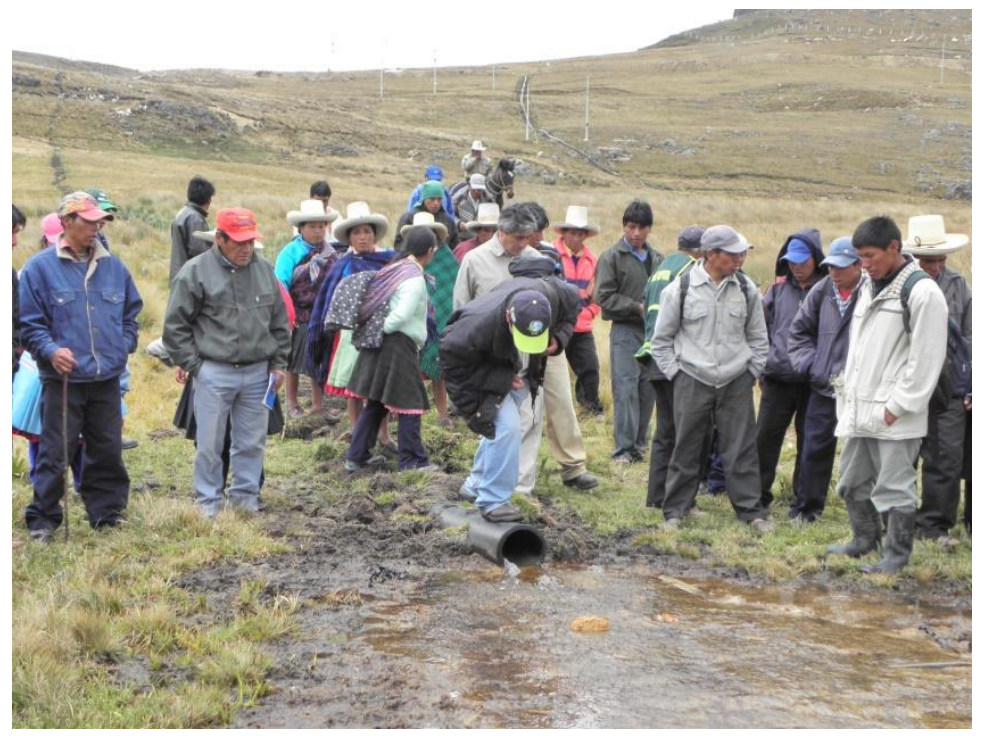

Fig. 10. Water conflict on the "Quinua" channel, Cajamarca-Perú (Red verde, 2011) 


\section{Poverty}

In the department of Cajamarca, about $68 \%$ of the population lives in rural areas, hence it is one of the most rural regions of Peru (De Echave and Diez, 2013). In addition, in the Sierra region of Peru, where the department of Cajamarca lies, poverty is $34.7 \%$, higher than the average in the country, which stands at $23.9 \%$. In the Sierra rural area poverty is $52.9 \%$ and in the Sierra urban area it is $16.2 \%$ (INEI, 2014).

The urban stakeholder group believes that the mining project will reduce the level of poverty, as it will generate direct and indirect economic income for families. While the rural stakeholder group, despite the fact that it has higher rates of poverty, believes the project will make them poorer, as it will destroy their economic base, which is based on agriculture and livestock.

\section{GDP per capita}

In the department of Cajamarca, in 1990, agricultural activity, with $42 \%$ of total production, was the mainstay of the regional economy, and mining accounted for only $5.9 \%$ of total production. In 2010 agricultural activity decreased to $20.1 \%$ and mining increased to $20.2 \%$. In addition trade activities, hostelry and manufacturing also increased. This growth mainly benefited urban areas (De Echave and Diez, 2013).

The urban stakeholder group believes that the GDP per capita in the cities will grow, as there will be much more investment in trade activities and other activities in urban areas. The rural stakeholder group does not believe that the GDP per capita in the rural areas will grow, due to the fact that they do not have other economic alternatives to agriculture and livestock, which will be affected by the mining project.

\section{Employment}

In recent years mining in Peru has experienced notable growth due to government promoted reforms on investment in mining. However, this economic sector does not generate significant direct employment, as it requires specialized labour. However, the mining industry generates indirect economic movement in other areas such as trade and services, which provides indirect employment (De Echave and Diez, 2013).

The urban stakeholder group strongly believes that the mining project will generate employment in urban areas, as there will be growth in economic sectors such as trade 
and services; in addition, the mining company affirms that it will train and hire people from the villages around the project area (Knight Piésold, 2010). However, the rural stakeholders group believes that when the mining project ends, it will leave serious environmental damage, and it will not be possible to use the land for agriculture or livestock, which means job losses in the rural area.

Based on what is analysed above, we believe that in order to prevent environmental conflict the following measures could be implemented:

- Due to the fact that the rural population has lost confidence in the mining company and central government, we propose the implementation of a permanent committee of environmental and social monitoring, in which the rural population is represented.

- We propose a change in legislation, so that EIA is not conducted or contracted by the mining company and that EIA must be contracted by the government and with the agreement of the affected population and the mining company.

- The mining company should study and consider other alternatives, which do not involve the use of natural lagoons, due to the fact that they provide ecological balance in the area and also represent the main causes of conflict over water.

- Taxes collected by the implementation of the project should be invested in social development projects in the area of influence, so that the population is able to perceive the benefits of the project.

- Diversification of economic activities in rural areas in order to create jobs to improve agriculture and livestock and take advantage of opportunities in the context of mining.

- The mining company and the government should explain and demonstrate to the directly affected population, that environmental and social impacts will be mitigated when the mining project is finished.

\subsection{The broader potential of the IGCEW method}

ECA methods are mainly developed as part of qualitative and quantitative approaches. In order to discuss the potential of the IGCEW method, we compare it below with the qualitative methods and then with the quantitative methods. 
First, we believe that the IGCEW method for ECA illustrated in this article could contribute to the improvement of the qualitative methods of ECA. For example, the study developed by Griewald and Rauschmayer (2014) or by Prenzel and Vanclay (2014), both conducted using qualitative methods, could be supplemented by applying the grey clustering method based on CTWF, which quantifies the qualitative information obtained from the stakeholder groups and then by a percentage system establishing a ranked order of social impact assessment for each stakeholder group. This knowledge can allow researchers to study environmental conflicts more accurately, because the procedure provides numerical information easy to analyse and to establish comparisons between the stakeholder groups involved in a given conflict.

Second, the IGCEW method for ECA applied in this article would also contribute to the improvement of the quantitative methods. For example, the study developed by AlMutairi et al. (2008), conducted under a quantitative method, could be supplemented by applying the entropy-weight method, which identifies the criteria with the greatest divergence factor between the stakeholder groups, and thus helps to define the causes of environmental conflict more closely, enabling researchers to find more accurate measures of conflict prevention.

\section{Conclusions}

The application of the IGCEW method for ECA to the mining project in Peru has made it possible to quantify the qualitative information provided by the three stakeholder groups identified, allowing us to establish the values of social impact for each stakeholder group objectively. In addition, the application of the IGCEW method determined the divergent criteria most likely to produce environmental conflicts between the stakeholder groups. The specific results obtained, we believe, could help analysts in the mining company or in the Peruvian government to seek appropriate measures to prevent conflict over the mining project.

We also strongly believe that the IGCEW method for ECA described in this article could be applied as an extension to the qualitative and quantitative methods for ECA, as it provides quantitative information of social impact for each stakeholder group by applying the grey clustering method based on CTWF. In addition, the results from the entropy-weight method can show clearly the criteria most likely leading to environmental conflicts. 
The limitations of the IGCEW method may be summarized as follows:

(1) It presents subjective aspects during information gathering and the establishment of limits of grey classes.

(2) The grey systems and Shannon entropy approaches are not widely diffused compared to approaches based on fuzzy logic or on statistics models.

(3) The calculations are a little tedious when processing data. This could be improved by implementing a computer system.

(4) As it is a new approach it needs to be validated in other contexts to improve its effectiveness.

In future research, the IGCEW method for ECA could be applied to other types of projects, such as water resources management, industrial projects, public construction projects, hydrocarbons exploitation projects, as well as be used to measure the social impact of public policies or governmental programs of conflict prevention.

\section{Acknowledgments}

This paper was reviewed by Przemysław Kaszubski, PhD, from the Faculty of English at the Adam Mickiewicz University in Poznan, Poland. The authors would like to thank him for his valuable comments and suggestions.

\section{References}

Al-Mutairi, M., Hipel, K., Kamel, M., 2008. Fuzzy preferences in conflicts. J. Syst. Sci. Syst. Eng. 17, 257-276.

Arun, E., 2008. Towards a shared systems model of stakeholders in environmental conflict. Int. Trans. Oper. Res.15, 239-253.

Augustsson, A., Filipsson, M., Öberg, T., Bergbäck, B., 2011. Climate change - An uncertainty factor in risk analysis of contaminated land. Sci. Total Environ. 409, 4693-4700.

Aznar, J., Guijarro, F., 2012. Nuevos Métodos De Valoración, Modelos Multicriterio, $2^{\mathrm{a}}$ ed. Universitat Politèctica de València, Valencia.

Barrow, C.J., 2010. How is environmental conflict addressed by SIA? Environ. Impact Assess. Rev. 30, 293-301.

Baykasoglu, A., Gölcük, I., 2015. Development of a novel multiple-attribute decision making model via fuzzy cognitive maps and hierarchical fuzzy TOPSIS. Inform. Sciences. 301, 75-98.

Bindu, C., Padmaja, M., Chandulal, J.A., 2010. Evaluating Web Sites Based on GHAP. Int. J. Computer Sci. Eng. 2, 674-679. 
Bolin, B., Collins, T., Darby, K., 2008. Fate of the verde: Water, environmental conflict, and the politics of scale in Arizona's central highlands. Geoforum. 39, 1494-1511.

Cao, C., Slobounov, S., 2011. Application of a novel measure of EEG non-stationarity as Shannon-entropy of the peak frequency shifting for detecting residual abnormalities in concussed individuals. Int. J. Clin. Neuropsyc. 122, 1314-1321.

Celendín libre, 2015. Lagoon "El Perol", Cajamarca-Perú. Retrieved from. https://celendinlibre.files.wordpress.com/2011/10/laguna-perol.jpg

Chang, Z., Qisen, Z., 2009. The assessment of the social, economic, and environmental impacts of expressway construction projects based on the DFGF Algorithm., Management and Service Science. MASS '09. International Conference On, Wuhan. 1-5.

Chen, S., Leng, Y., Mao, B., Liu, S., 2014. Integrated weight-based multi-criteria evaluation on transfer in large transport terminals: A case study of the Beijing South Railway Station. Transport. Res. A-Pol. 66, 13-26.

Corbetta, P., 2007. Metodología y Técnicas de Investigación Social. McGRAW-HILL, Madrid.

Correia, D., 2007. The sustained yield forest management act and the roots of environmental conflict in Northern New Mexico. Geoforum. 38, 1040-1051.

De Echave, J., Diez, A., 2013. Más allá de Conga. Red Peruana por una Globalización con Equidad - RedGE, Lima - Perú.

Deng, J., 1985. Generation functions of grey systems. Fuzzy Mathematics. 5, 11-22.

El Comercio, 2015. Enfrentamiento en Cajamarca deja un consejero regional herido. Retrieved from. http://elcomercio.pe/peru/cajamarca/enfrentamiento-conga-deja-consejero-regionalherido-noticia-1808009? ref=flujo_tags_322786\&ft=nota_3\&e=titulo

Fagbote, E.O., Olanipekun, E.O., Uyi, H.S., 2014. Water quality index of the ground water of bitumen deposit impacted farm settlements using entropy weighted method. Int. J. Environ. Sci. Technol. 11, 127-138.

Fontaine, G., 2010. The effects of energy co-governance in Peru. Energy Policy. 38, 2234-2244.

Franks, D.M., Vanclay, F., 2013. Social Impact Management Plans: Innovation in corporate and public policy. Environ. Impact Assess. Rev. 43, 40-48.

Griewald, Y., Rauschmayer, F., 2014. Exploring an environmental conflict from a capability perspective. Ecol. Econ. 100, 30-39.

Grufides, 2015. Observatorio de conflictos Cajamarca, conflicto minero Conga. Retrieved from. http://www.grufides.org/sites/default/files//Documentos/fichas_casos/CONFLICTO\%20MINERO\%20C ONGA.pdf

Hamilton, S.H., ElSawah, S., Guillaume, J.H., Jakeman, A.J., Pierce, S.A., 2015. Integrated assessment and modelling: Overview and synthesis of salient dimensions. Environ. Modell. Softw. 64, 215-229.

Heidari Bafroui, H., Ohadi, A., 2014. Application of wavelet energy and Shannon entropy for feature extraction in gearbox fault detection under varying speed conditions. Neurocomputing. $133,437-445$. 
INEI, 2014. Instituto Nacional de Estadística e Informática del Perú. 2014. Retrieved from http://www.inei.gob.pe/

Ji, Y., Huang, G.H., Sun, W., 2015. Risk assessment of hydropower stations through an integrated fuzzy entropy-weight multiple criteria decision making method: A case study of the Xiangxi River. Expert Syst. Appl. 42, 5380-5389.

Karjalainen, T.P., Järvikoski, T., 2010. Negotiating river ecosystems: Impact assessment and conflict mediation in the cases of hydro-power construction. Environ. Impact Assess. Rev. 30, 319-327.

Kemper, J., Schilke, O., Reimann, M., Wang, X., Brettel, M., 2013. Competition-motivated corporate social responsibility. J. Bus. Res. 66, 1954-1963.

Knight Piésold, 2010. Estudio de Impacto Ambiental. Proyecto Conga. Minera Yanacocha S.R.L.. Perú.

Kou, G., Sun, Q., Peng, Y., 2011. An Entropy-Weighted Clustering Method for Environmental Pollution Assessment in China, in Shi, Y., Wang, S., Kou, G., Wallenius, J. (Eds.), New State of MCDM in the 21st Century. Springer, Berlin, pp. 177-188.

Leng, Y., Kou, C., Zhou, N., Li, Q., Liang, Y., Xu, Z., Chen, S., 2012. Evaluation on Transfer Efficiency at Integrated Transport Terminals through Multilevel Grey Evaluation. Procedia Social and Behavioral Sciences. 43, 587-594.

Li, C., Chen, K., Xiang, X., 2015. An integrated framework for effective safety management evaluation: Application of an improved grey clustering measurement. Expert Syst. Appl. http://dx.doi.org/10.1016/j.eswa.2015.02.053

Liu, S., Lin, Y., 2010. Grey Systems: Theory and Applications. Springer, Berlin.

Luyet, V., Schlaepfer, R., Parlange, M.B., Buttler, A., 2012. A framework to implement Stakeholder participation in environmental projects. J. Environ. Manage. 111, 213-219.

Madani, K., Rouhani, O., Mirchi, A., Gholizadeh, S., 2014. A negotiation support system for resolving an international trans-boundary natural resource conflict. Environ. Modell. Softw. 51, 240-249.

MINAM, 2011. Ministerio del Ambiente. Informe Nº01-2011. Perú.

Prenzel, P.V., Vanclay, F., 2014. How social impact assessment can contribute to conflict management. Environ. Impact Assess. Rev. 45, 30-37.

Red verde, 2011. Water conflict on the "Quinua" channel. Retrieved from. http://caballeroredverde.blogspot.com.es/2011/09/usuario-de-canal-quinua-marchan-en.html

Sánchez, W., 2011. ¿Por qué el proyecto conga es inviable?. Universidad Nacional de Cajamarca. Perú.

Saqalli, M., Thiriot, S., Amblard, F., 2010. Investigating social conflicts linked to water resources trhough agent-based modelling. NATO Science for Peace and security series. 75, 142157.

Shannon, C.E., Weaver, W., 1947. The Mathematical Theory of Communication. Urbana, The University of Illinois Press. 
Shemshadi, A., Shirazi, H., Toreihi, M., Tarokh, M.J., 2011. A fuzzy VIKOR method for supplier selection based on entropy measure for objective weighting. Expert Syst. Appl. 38, 12160-12167.

Silva-Macher, J.C., Farrell, K.N., 2014. The flow/fund model of Conga: exploring the anatomy of environmental conflicts at the Andes-Amazon commodity frontier. Environ. Dev. Sustain. $16,747-768$.

Srivastav, R., Simonovic, S., 2014. An analytical procedure for multi-site, multi-season streamflow generation using maximum entropy bootstrapping. Environ. Modell. Softw. 59, 5975 .

Wang, T., Lee, H., 2009. Developing a fuzzy TOPSIS approach based on subjective weights and objective weights. Expert Syst. Appl. 36, 8980-8985.

Warnaars, X.S., 2012. Why be poor when we can be rich? Constructing responsible mining in El Pangui, Ecuador. Resour. Policy. 37, 223-232.

Wei, J., Zhou, L., Wang, F., Wu, D., 2015. Work safety evaluation in Mainland China using grey theory. Appl. Math. Model. 39, 924-933.

Wikimedia Commons, 2014. File: Peru_-_(template).svg. Retrieved from. http://es.wikipedia.org/wiki/Departamento de Cajamarca\#mediaviewer/File:Peru_-

Cajamarca_Department_(locator_map).svg

Wittmer, H., Rauschmayer, F., Klauer, B., 2006. How to select instruments for the resolution of environmental conflicts?. Land Use Policy. 23, 1-9.

Xie, M., Yang, Y., 2011. Cost Risk Assessment of Construction Projects Based on EntropyWeighted Matter-Element Model. Adv. Mat. Res. 168-170, 2402-2405.

Yang, J., Ryan, C., Zhang, L., 2013. Social conflict in communities impacted by tourism. Tourism. Manage. 35, 82-93.

Zadeh, L.A., 1965. Fuzzy sets. Inform. Control. 8, 338-353.

Zeleny, M., 1996. Multiple Criteria Decision Making. Springer, New York.

Zhang, Y., Ni, J., Liu, J., Jian, L., 2014. Grey evaluation empirical study based on center-point triangular whitenization weight function of Jiangsu Province industrial technology innovation strategy alliance. Grey Systems: Theory and Application. 4, 124-136.

Zhang, L.N., Wu, F.P., Jia, P., 2013. Grey Evaluation Model Based on Reformative Triangular Whitenization Weight Function and Its Application in Water Rights Allocation System. The Open Cybernetics \& Systemics Journal. 7, 1-10.

Zitnick, L., Kanade, T., 2004. Maximum Entropy for Collaborative Filtering. In ACM Proceedings of the 20th Conference on Uncertainty in Artificial Intelligence, 636-643. 